\title{
Focal Visual Attention Produces Illusory Temporal Order and Motion Sensation
}

\author{
OKIHIDE HIKOSAKA,* SATORU MIYAUCHI,* SHINSUKE SHIMOJO $\dagger$
}

Received 23 April 1992; in revised form 16 November 1992

\begin{abstract}
Spatial attention was studied using a new visual illusion of motion: a line, which was presented physically at once, was perceived to be drawn from one side when attention had been captured to that side of the line by a preceding visual cue stimulus. By comparing with a temporal order task, we showed that the line-motion illusion was produced by acceleration of visual information processing at the locus of attention. The results suggest that the facilitatory effect of attention is exerted at relatively early stages of visual information processing where visual signals are to be fed into the motion detecting mechanism.
\end{abstract}

Visual attention Line-motion illusion Motion perception Sustained/transient features Dichoptic presentation

\section{INTRODUCTION}

Selection is fundamental to our voluntary action. We are subject to continual sensory bombardment simultaneously from different sensory receptors, yet our action is limited to the physical dimensions of our body and often is aimed at one or few objects. Here arises the need for selection. Eye movement exemplifies the manyto-one relationship between sensory inputs and motor outputs. Our visual field is full of shapes, colors, textures, motions, and etc., yet the central fovea is directed to limited visual objects by saccade and smooth pursuit. What makes a saccade directed to an object A, not B, $C$ or $D$ ? There must be a reason, if not purely stochastic, for this selection. What, then, determines this selection, and where in the neural pathways does it occur? We know that the selection affects not only our action but also our perception so that only selected objects reach to the threshold of our consciousness. The perceptual selection, which we usually call attention, can thus be dissociated from action. Our environment may be selected, without immediate action, for construction of internal representations.

Because attention is a modulatory process, we cannot see attention per se. Only comparison between two perceptual states, with attention and without attention, based on overt behavioral responses or a subjective reports would reveal the presence of attention. The approach has been successful in visual spatial attention, especially when attention is temporarily induced passively by a preceding visual stimulus. Psychophysical studies have shown that the efficiency of perception of an

\footnotetext{
*Laboratory of Neural Control, National Institute for Physiological Sciences, Myodaiji-cho, Okazaki 444, Japan.

†Department of Psychology, University of Tokyo, Tokyo 153, Japan.
}

object is increased at the expense of others when the subject pays attention to it. Several measures have been used to characterize the effect of attention, including (1) sensitivity, (2) resolution, and (3) latency of perception. The sensitivity of perception is typically examined by utilizing signal detection theory. When a visual cue is presented beforehand to indicate the location of a target stimulus, the sensitivity for perception (either detection or discrimination) of the target becomes higher than otherwise equivalent stimulus which is not cued (Bashinski \& Bacharach, 1980; Egly \& Homa, 1984; Downing, 1988; Müller \& Rabbit, 1989). The changes in perceptual resolution can be measured as changes in positional accuracies, such as vernier acuity (Nakayama \& Mackeben, 1989). The changes in perceptual latency have been examined in two ways, (a) by measuring reaction time (Eriksen \& Hoffman, 1972; Posner, 1980) and (b) by asking perceptual temporal order (Sternberg \& Knoll, 1973). Based on the results obtained using these methods, it seems reasonable to define attention as a process by which limited sensory information is brought into perception with relatively greater magnitude and efficiency.

We now describe a novel technique that enables us to detect and directly visualize-unlike the previous methods - the spatial gradient of visual attention. It was originated from our discovery of a visual illusion which, to our knowledge, has never been reported (though see Kanizsa, 1979). We noticed that, when we present a line physically at once, its onset does not always appear instant. It frequently appears to be drawn in either one of the directions, thus we perceive a motion in the line. The motion sensation is particularly strong and consistent when a visual stimulus (e.g. light spot) is presented at either one of the terminators of the line before the onset of the line; the motion 
is from the side of the visual stimulus. We suggest that the illusory motion sensation might reflect visual spatial attention.

Underlying this idea were two lines of psychophysical findings. First, focal visual attention creates an illusory temporal asynchrony of visual information to reach perception such that the attended visual stimulus is perceived prior to non-attended stimuli (Sternberg \& Knoll, 1973). Second, central motion detecting mechanisms presumably creates motion sensation based on asynchronous and spatially displaced visual inputs (Braddick, 1980; Nakayama, 1985). Taken together these two well-known facts, it is intriguing to ask whether the attention modulates a stage early enough in the visual pathway so that it can produce motion sensation. We carried out the present study to demonstrate that the motion sensation in the line is indeed produced by the modulating effect of attention.

This article is organized such that the reader can follow the logical procedure by which we have integrated these two psychological phenomena, attention and motion. First, we studied the effects of focal attention on the temporal order judgment of a pair of visual stimuli. We drew attention of the human subject by presenting or extinguishing a visual stimulus as a cue. In agreement with previous studies (Sternberg \& Knoll, 1973; Maylor, 1985; Stelmach \& Herdman, 1991), we showed that focal attention locally accelerates visual information processing. Here, however, the judgment was still nothing to do with early visual processes, such as that of motion. In a second experiment, we modified the first task by presenting an array of visual stimuli, instead of two. The temporal order judgment could now rely on a motion sensation, i.e. apparent motion, over the array of visual stimuli. What was important in this seemingly trivial modification was that by recruiting the motion mechanisms we could greatly increase the sensitivity of the temporal-order judgment. We thought that the improvement in this direction might be achieved by making the array infinitely finer. The array was thus replaced with a simple line in the next experiment so that a contiguous motion was perceived. We then found that the cue effect was the same in a dichoptic siluation, suggesting that the attention shift occurs at or after binocular convergence.

Finally, using this technique we demonstrated that both onset and offset of visual stimuli induced attention but the rising time course of attention differed in these two situations. When the onset and the offset occurred at the same time at different locations, however, a strong interaction occurred such that the offset-induced attention was dominated and suppressed by the onset-induced attention. This seemed to be related to the perceptual impression of the onset/offset of the stimuli, i.e. apparent motion.

\section{GENERAL METHODS}

The subject sat in front of a monochrome display of a tachistoscope (IWATSU ISEL, IS701-B) in a dark room. This equipment was used mostly for its $1-\mathrm{msec}$ temporal resolution. For some experiments where no such resolution was required, a personal computer (NEC PC-9801RA) was used. The observation distance was either 57 or $114 \mathrm{~cm}$. The experiment was performed in a dark room. The luminance of the visual stimuli was $52 \mathrm{~cd} / \mathrm{m}^{2}$, unless otherwise specified. They were displayed on a dark background. The subject's head was not fixed in most of the experiments. Eye fixation was monitored in selected experiments using an infra-red eye movement monitoring system (RMS HIROSAKI, R-21C-A). In such cases the subject's head was constrained using a chin rest and a bite board. In all the experiments, the subject was explicitly instructed not to pay attention voluntarily to the stimulus.

\section{EXPERIMENTS}

\section{Illusory Temporal Order Reflects Attention}

When we receive more than two sensory inputs at once, we do not necessarily perceive that they are simultaneous. An important factor influencing the temporal order judgment is intensity: the weaker stimulus tends to be perceived later than the stronger one (Roufs, 1963). What then happens if two sensory stimuli are physically identical with equal intensities? We still sometimes perceive them as being asynchronous, and the direction of asynchrony is often unpredictable. The sources of the asynchrony must be psychological; attention is a critical factor.

\section{Experiment 1: Illusory Temporal Order Induced by Onset of Visual Stimulus}

First, we examined how much the temporal order of visual perception is modified by stimulus-induced attention. As illustrated in Fig. 1, we presented two visual stimuli (test stimuli) in different sequences with different intervals, and asked the subject to judge which stimulus came on earlier. Before the stimuli we presented a small spot of light (cue stimulus) to draw the subject's attention.

\section{Methods}

Subjects. Four subjects participated in this experiment; two were the authors (SM, OH) and the other two subjects (YY, HI) were experienced psychologists but did not know the purpose of the experiment.

Apparatus. The tachistoscope (IWATSU ISEL, IS701-B) was used. It can display up to 32 frames of pictures (P31 phosphor) which are pre-arranged sequentially, at random, or depending on the key response of the subject. In the following experiments, unless otherwise stated, the frame rate was set to be $500 \mathrm{~Hz}$.

Stimuli. The fixation point and the stimuli $\left(52 \mathrm{~cd} / \mathrm{m}^{2}\right)$ were presented on a dark background $\left(<0.2 \mathrm{~cd} / \mathrm{m}^{2}\right)$. The fixation point was a small dot $(0.05 \times 0.05 \mathrm{deg})$. We used two types of visual stimuli: cue stimulus and a pair of target stimuli. The cue stimulus was a small spot 

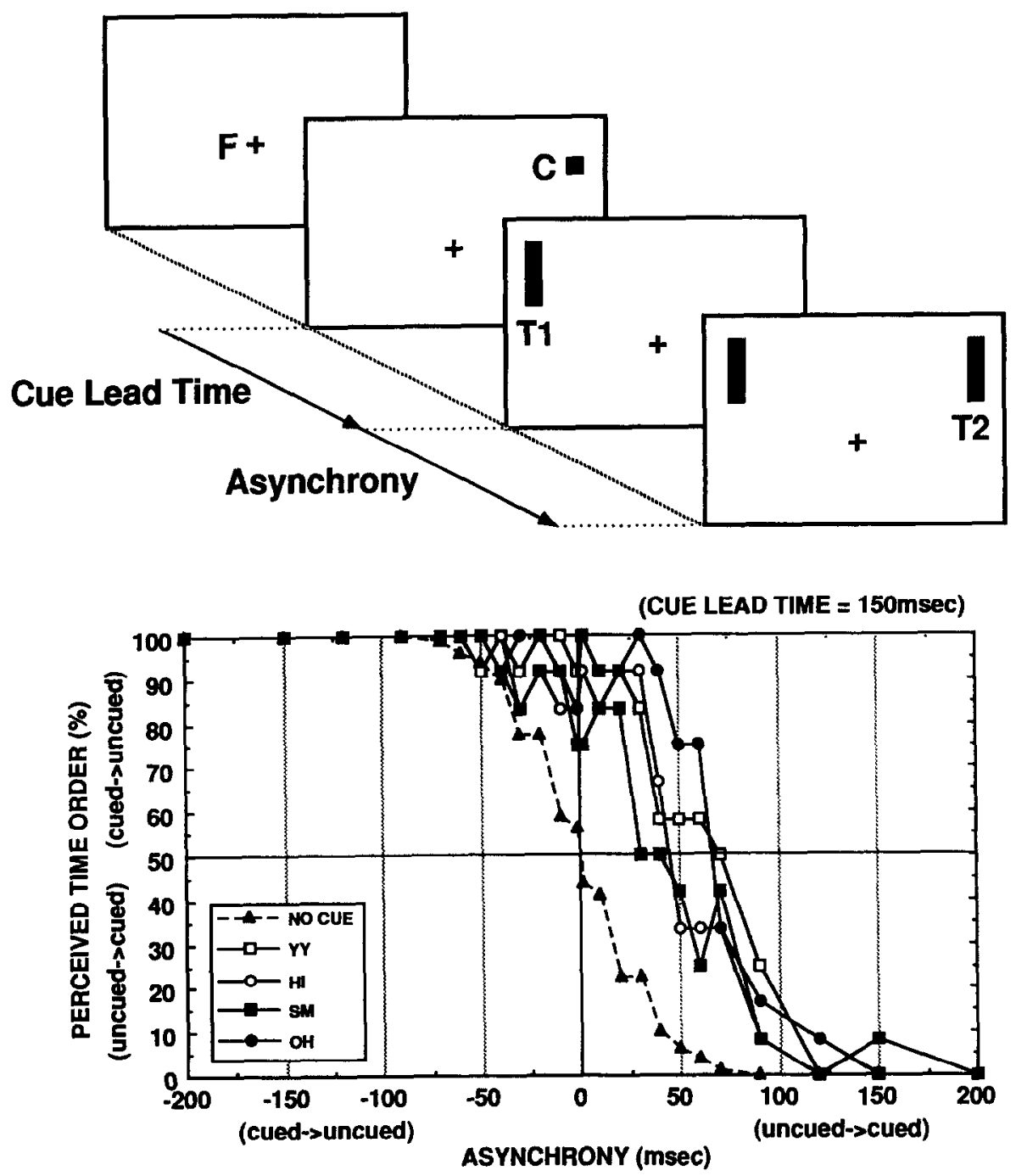

FIGURE 1. Stimulus onset induces acceleration of local visual information processing. Top: temporal order task to measure local facilitatory effects induced by stimulus onset. While the subject was fixating a central spot (F), another spot of light (cue, C) came on at either one of two possible sites (right and left). After a time delay (cue lead time) a vertical short bar (T1) appeared in either one of the two cue locations (cued side or uncued side), followed by the appearance of another bar at the other cue location (T2) with a randomized asynchrony $(0-200 \mathrm{msec})$. The subjects task was to judge which bar came on first (two-alternative forced-choice paradigm). The cue lead time was fixed in a given block of experiment; at 50, 150, 400, or $1600 \mathrm{msec}$. Bottom: the percentage of trials in which the cued bar was judged to appear prior to the uncued bar was plotted against the physical asynchrony between the two bars; the asynchrony was $(+)$ when the uncued bar preceded (physically) the cued bar, whilc ( - ) when the cued bar preceded. Data for $150 \mathrm{msec}$ cue lead time were plotted here. Data from four subjects are shown with different symbols. Twenty trials were obtained for each asynchrony in each subject. Data with no cue are also plotted for comparison (dashed line; averaged across the four subjects); for this set of data, the averaged psychometric function was obtained only for the positive asynchronies (because in this case there was no such distinction between cued and uncued sides). The function was then flipped and symmetrically replotted with respect to the original point of the graph just for easier comparison.

$(0.05 \times 0.05 \mathrm{deg})$; the target stimulus was a rectangle oriented vertically $(0.05 \times 1.0 \mathrm{deg})$. The cue stimulus was located such that it was completely occluded by the target stimulus, when presented on the same side. The pair of the target stimuli were presented in a horizontally symmetric manner (separated by $10.7 \mathrm{deg}$ ) and slightly above $(0.75 \mathrm{deg})$ the level of the fixation point (see Fig. 1). The observation distance was $117 \mathrm{~cm}$. Eye movements were monitored in selected sessions of experiment using the infra-red eye movement monitoring system (RMS HIROSAKI, R-21C-A). In such cases the subject's head was constrained using a chin rest and a bite board.
Procedure. The subject initiated each trial by pressing a key which was followed by the appearance of the fixation point. The subject had to keep fixating at the fixation point throughout the trial. The cue stimulus then appeared randomly either on the right or left side. After a time delay (cue lead time) one of the target stimuli came on randomly on the side same as or opposite to the cue. This is followed with a time delay (asynchrony) by the onset of the other target stimulus. The asynchrony was defined as the time interval from the onset of the target on the uncued side to the onset of the target on the cued side; it can be + or - depending on the side of the first target with respect to the cue. The 
subject's task was to report which of the target stimuli came on first by pressing one of the two keys. It was a two-alternative forced-choice (2AFC) task. In this and the following experiments, the subject was required not to pay attention voluntarily to a specific location or a specific stimulus feature.

The experiment was composed of blocks which were carried out over several days. Within each block the cue lead time was fixed $(50,150,400$, or $1600 \mathrm{msec})$, while the asynchrony was randomized in a range between -200 and $+200 \mathrm{msec}$ (24 steps of asynchronies); in a separate block of experiment, no cue was presented (no-cue condition). Twelve trials were tested for each asynchrony, so that each block consisted of a total of 288 trials. The sides were equated such that the cue appeared on the right side in half of the 20 trials and on the left side in the other half. The variable in question was the temporal order of the target stimuli with respect to the side of the cue; the temporal order with respect to the absolute side (right or left) was not analyzed in this study.

Analyses. We first calculated the percentage of trials in which the target stimulus on the cued side was perceived to be earlier at each asynchrony. This yielded a psychometric function against the asynchrony for each cue lead time. Using a probit analysis (Finney, 1971) we then calculated the point of subjective equality (PSE).

\section{Results}

Figure 1 shows the psychometric functions obtained from four subjects; the perceived temporal order (expressed as probability) was plotted against the asynchrony between the two test stimuli. The dotted curve indicates the control data under no-cue condition which were averaged across the subjects. As expected, the percentage of perceived temporal order was $50 \%$ at the zero asynchrony. When preceded by the cue stimulus by $150 \mathrm{msec}$, the psychometric function shifted to the right. With no asynchrony, for instance, the test stimulus at the cued location (thereafter called "cued stimulus") was more often perceived to be prior to the test stimulus at the uncued location ("uncued stimulus"). For the perceived temporal order to be the chance level, the uncued stimulus had to occur before the cued stimulus by 30-70 msec. These time values were calculated using the probit analysis and will thereafter be called "point of subjective equality" (PSE).

The result suggests that the information from the cued stimulus reached perception earlier by $30-70 \mathrm{msec}$ than the information from the uncued stimulus. The attentional effect then can operationally be defined as this margin. What we observed in this experiment was passive, stimulus-induced attention.

We noticed that the PSE value changes with the cue lead time (Fig. 2). A peak of the PSE was obtained at the cue lead time of $150 \mathrm{msec}$ in all four subjects, indicating that the effect of attention has a transient component. The PSE remained positive at longer cue lead times in three subjects, suggesting the presence of a sustained component as well.

\section{Discussion}

The result shows that the onset of a visual stimulus (cue) accelerates local visual information processing and hence another visual stimulus presented subsequently at the locus of the visual cue is perceived earlier. The maximum perceptual asynchrony produced by the attentional bias was $30-70 \mathrm{msec}$ (with some individual differences) in our study. These values are similar to the ones obtained in other studies using visual stimuli (Maylor, 1985; Stelmach \& Herdman, 1991) and a study using auditory/tactile stimuli (see Sternberg \& Knoll, 1973).

We argue that the asynchrony effect reflects attention which is produced by the onset of a visual stimulus. That an abrupt visual onset draws attention is our daily experience and has been supported by psychological experiments (Eriksen \& Hoffman, 1972; Posner, 1980;

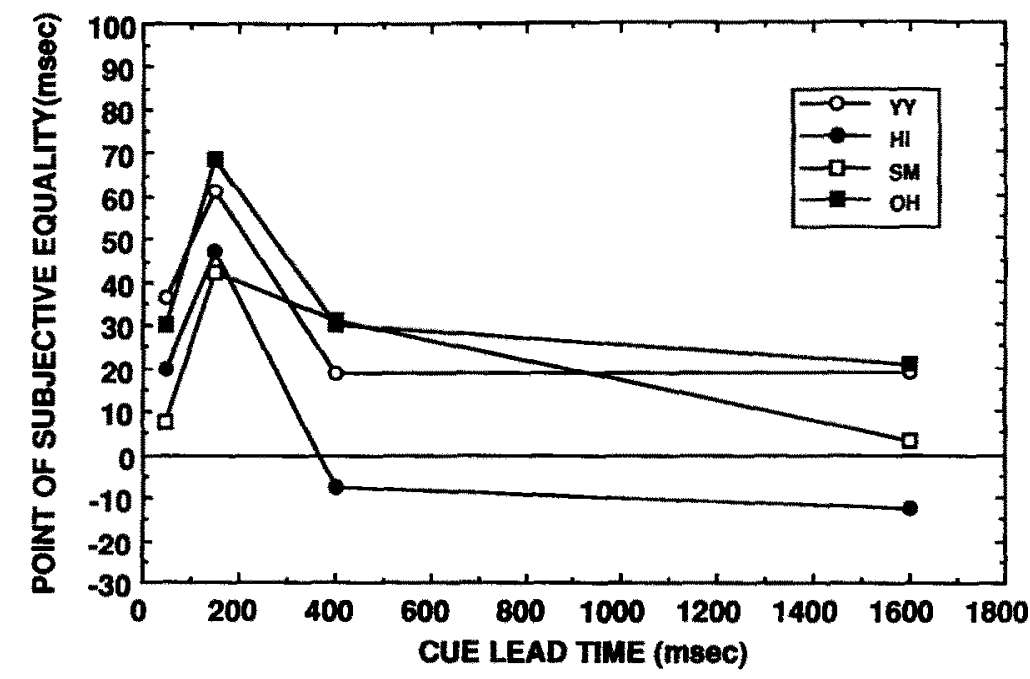

FIGURE 2. Local visual acceleration induced by stimulus onset depends on cue lead time. Points of subjective equality (PSE) for cancellation of apparent temporal order were obtained using a probit analysis based on the data such as shown in Fig. 1 , and they are plotted against cue lead time. Positive values indicate that information from the cued bar (cue-on side) reached perception earlier than that from the uncued bar. Data from four subjects are shown with different symbols. 
Yantis \& Jonides, 1984; Remington, Johnston \& Yantis, 1992). One might argue that this is unrelated to attention because the subject was non-attentive, but the state of mind after the cue stimulus was clearly attentive as judged by the asynchrony of visual processing. In this study we will thus use the term "attention" strictly in this functional sense.

However, before concluding that this is indeed the effect of attention, we need to exclude the possibility that the signals from the visual cue and the target stimulus might simply summate at early stages of visual information processing, thereby producing earlier perception. In order to produce perceptual asynchrony of $20 \mathrm{msec}$, for example, the intensities of two visual stimuli with the same sizes must be different in the order of 10 (Roufs,
1963). In contrast, the spot of light we used for the visual cue was much smaller than the target stimuli (bars) and thus its contribution to the perceived intensity would be negligible.

Another possible argument against the attention hypothesis would be that the onset of the visual cue might be erroneously taken to be the onset of the target stimulus. This is also unlikely because at the shortest cue lead time $(50 \mathrm{msec})$ the visual cue was generally unnoticed presumably due to backward masking, yet the perceptual asynchrony was present. One might still argue however that different mechanisms are at work for identification of the visual cue and temporal order judgment. These possible objections would not be applicable to the following experiment.
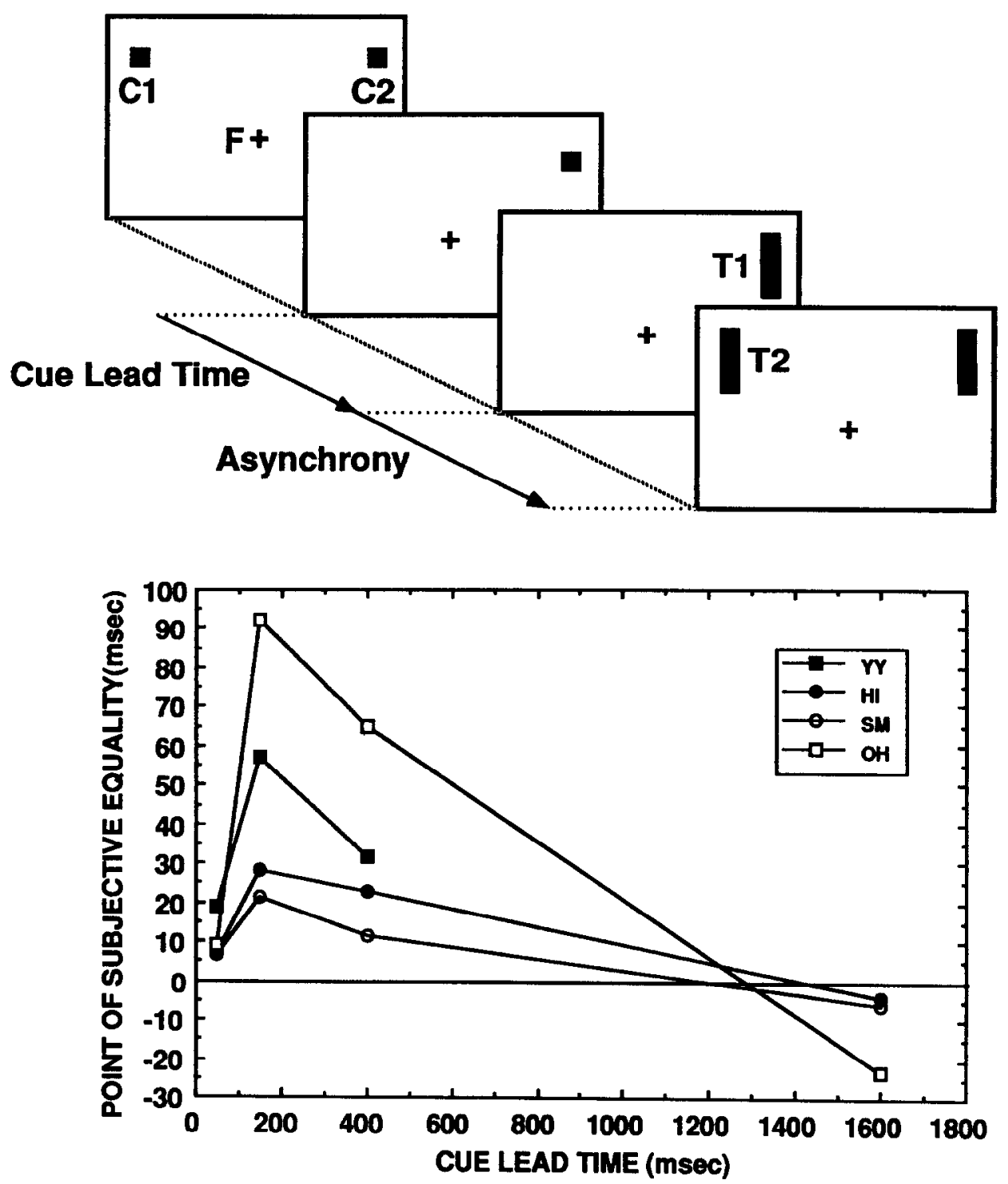

FIGURE 3. Stimulus offset induces acceleration of local visual information processing. Top: temporal order task to measure local facilitatory effects induced by stimulus offset. The task trial started with two spots (cue stimuli, $\mathrm{C} 1$ and $\mathrm{C} 2$ ) on. While the subject was fixating a central spot (F), one of the cue stimuli went off. After a time delay (cue lead time) a vertical short bar appeared in either one of the two cue locations (T1), followed by the appearance of another bar at the other cue location (T2) with a randomized asynchrony $(0-200 \mathrm{msec})$. The subjects task was to judge which bar came on first. Bottom: points of subjective equality for temporal order were obtained in the same way as in Figs 1 and 2. Positive values indicate that information from the cued bar (cue-off side) reached perception earlier than the that from uncued bar. Data from four subjects are shown with different symbols. 
Experiment 2: Illusory Temporal Order Induced by Offset of Visual Stimulus

The results so far indicate that attention is drawn automatically to the location where a visual object appeared. Does any change in visual environment induce attention? An extreme example will be disappearance of an object. We thus designed the next experiment as illustrated in Fig. 3. An experimental trial started with two cue stimuli on so that no asymmetry of attention was expected. In order to manipulate attention we extinguished one of the cue stimuli before the test stimuli appeared. The subjects task was again to judge the temporal order of the two test stimuli.

\section{Methods}

The same four subjects participated in this experiment. The apparatus and the stimuli were identical with Expt 1.

Procedure. The procedure was the same as Expt 1 except for the presentation of cue stimuli. Each trial started with the presentation of the fixation point and two cue stimuli. One of the cue stimuli then went off randomly either on the right or left side. This was followed with a cue lead time (fixed throughout a block) by the sequential presentation of the target stimuli in the same way as in Expt 1 . The subjects task was again to report which of the target stimuli came on first (2AFC). The configuration and analyses of the experiment was the same as Expt 1.

\section{Results}

Based on the psychometric function obtained for each subject and for each cue lead time (similar to Fig. 1, but not shown), we calculated the PSE value. Figure 3 summarizes the results. The PSE curve for every subject had a single positive peak at the cue lead time of $150 \mathrm{msec}$. This indicates that attention was induced at the location where the cue disappeared. The PSE values at $50 \mathrm{msec}$ were smaller than in case of the cue stimulus onset (see Fig. 2), suggesting that the stimulusoff-induced attention is slower to develop than the stimulus-on-induced attention. A more critical difference, however, was found at longer cue lead times. The PSE values at $1600 \mathrm{msec}$ were invariably negative, suggesting that the attentional benefit was now on the side where a cue stimulus remained.

\section{Discussion}

The result indicates that a visual offset also leads to perceptual asynchrony in such a way that focal attention is induced at the locus of the visual offset. Unlike for the effect induced by cue-on (Expt 1), the asynchrony here cannot be attributed to the imbalance of stimulus intensity because the time-averaged intensity of stimulus is reduced on the cue-off side.

The reversal of the asynchrony effect at the long cue lead time was consistent across subjects. This may imply attention-related inhibition, i.e. "inhibition of return"
(Posner, Rafal, Choate \& Vaughan, 1985). However, the effect was weaker than the initial transient one and did not reach a significant level, and awaits for further analysis using a more sensitive method (see Expt 4).

\section{Illusory Motion Reflects Attention}

The temporal order task has revealed temporal asynchrony of visual signals produced by attention. However, the temporal order judgment is difficult and suffers from a considerable amount of uncertainty. This was illustrated in the psychometric functions (see Fig. 1) by their wide uncertain ranges (at least $\pm 50 \mathrm{msec}$ ). The uncertainty arises because the two sensory stimuli should be perceived as independent events before they are to be judged in terms of temporal order. When, instead, their relation is directly perceived, the uncertainty could be reduced to a considerable extent (Sternberg \& Knoll, 1973). For example, the temporal order of two sound clicks, delivered to different ears, can be discriminated because a fused sound image whose location is closer to the preceding sound is produced in the head (Green \& Henning, 1969). As for visual perception, sequential stimulation may produce the impression of movement from the preceding stimulus to the following one (Wertheimer, 1912).

We therefore attempted to have the motion detectors detect the asynchrony of visual inputs which is physically absent but is created by attention. Behind this hypothesis is the assumption that the attentional modulation of visual information processing occurs early enough; i.e. before the signals reach the mechanisms for motion detection. We recruited the motion detecting mechanisms, first by presenting an array of visual stimuli (Expt 3 ) and finally by presenting a single line (Expt 4).

\section{Experiment 3: Apparent Motion in an Array of Visual Stimuli Induced by Attention}

If an array of vertical bars were presented in sequence, a motion sensation is perceived in the array. Before the sequential appearance of the array, we presented a small spot of light (cue stimulus) on the right or left side to induce attention. As expected from the temporal order task, when the bars appeared at once, a motion was perceived from the side where the cue stimulus was presented. By physically presenting the array of bars from the side opposite to the cue and and by increasing the time interval between the bars, the motion sensation decreased and finally was reversed. Thus, the illusory asynchrony or motion could be cancelled out by physical asynchrony or motion. Such a reversal point (PSE) was taken as an objective estimate of the attentional effect produced by the cue stimulus. The sequence of stimuli is illustrated in Fig. 4.

\section{Methods}

Subjects. Five subjects participated in this experiment; three were the authors (SM, SS, OH) and the other two subjects (IM, HI) were experienced psychologists but did not know the purpose of the experiment. 

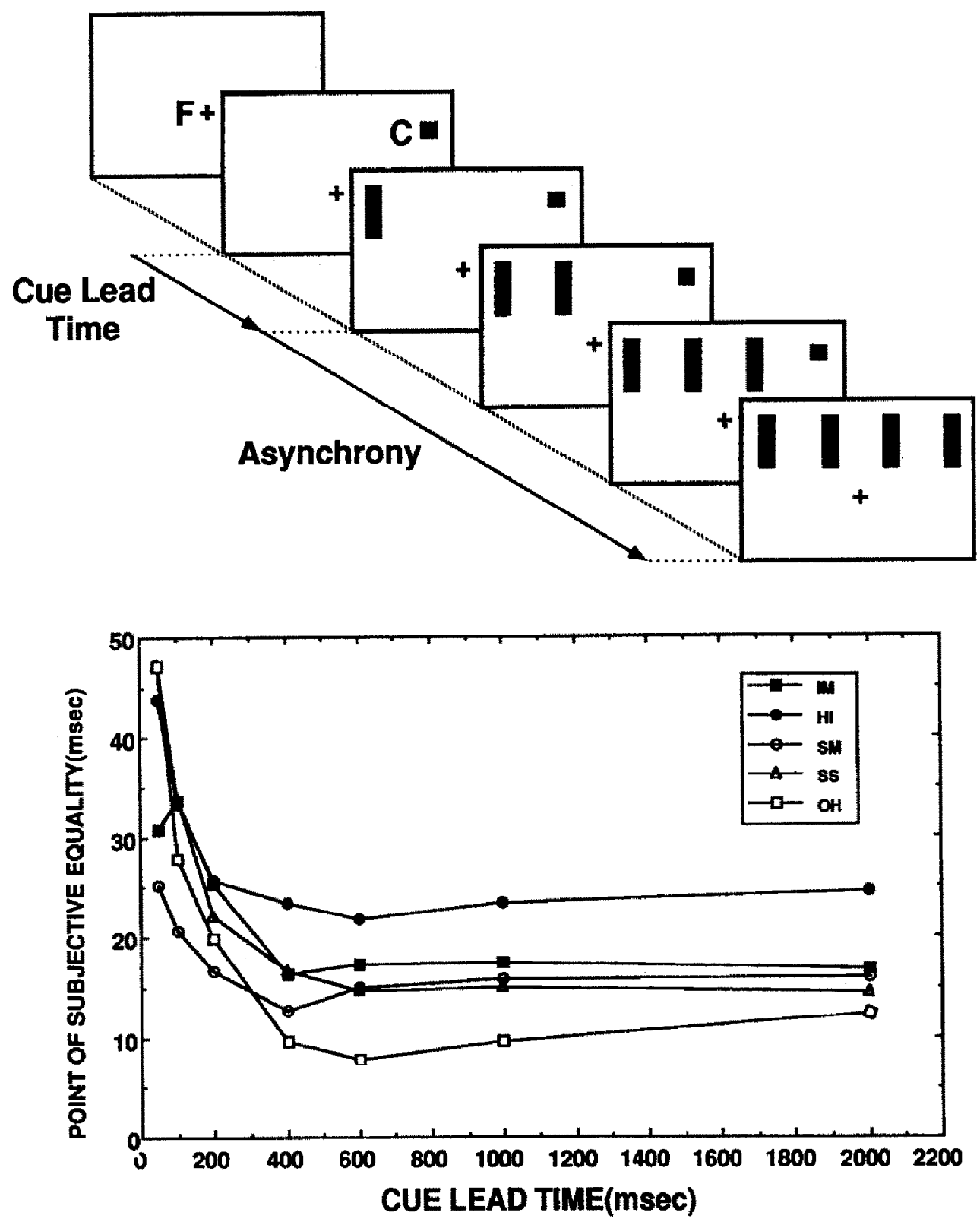

FIGURE 4. Motion sensation is induced in an array of visual stimuli by stimulus onset. Top: just as the original stimulus-on case (Fig. 1), a small spot of light (cue, C) appeared on the right or left side. After a cue lead time, a vertical bar appeared on the side opposite to the cue, followed by the appearance of three other bars sequentially toward the cue (the last bar was superimposed on the cue). The asynchrony between the onsets of the bars was fixed for each trial but randomized between trials $(2,6,10, \ldots, 34,38 \mathrm{msec})$. Unlike the temporal order task comparing two bars, an apparent motion was perceived by the sequential appearance of the bars. The subject was asked to report the direction of the motion. The cue lead time was randomized in each block of experiment. Bottom: points of subjective equality for cancellation of motion were obtained using a probit analysis and they were plotted against the cue lead time. The ordinate indicates the asynchrony between the bars which could cancel the illusory motion sensation. Data from five subjects are shown with different symbols.

Apparatus and stimuli. The stimuli were generated and presented with the tachistoscope in a dark room. The stimuli were similar to those used in Expts 1 and 2, except that four target stimuli, instead of two, were presented in a sequential manner (Fig. 4). The location of the cue stimulus corresponded to either the rightmost target or the leftmost target, which were separated by $4.0 \mathrm{deg}$; thus the separation between each target was 1.33 deg.

Procedure. The initial part of the stimulus sequence was the same as Expt 1 . The onset of the cue stimulus was followed with a cue lead time (fixed throughout a block) by the onset of the target at the side opposite to the cue. The other three targets were presented sequentially toward the cue stimulus until the last target masked the cue stimulus. The subject's task was to report in which direction motion was perceived over the array (2AFC task).

The experiment was composed of five blocks which were carried out over several days. Within each block the cue lead time was randomized $(50,100,200,400,600$, 1000 , or $2000 \mathrm{msec}$ ). The time interval between the target onsets was fixed for each trial but randomized within a block of experiment $(2,6,10, \ldots, 34,38 \mathrm{msec})$. Thus, the time interval between the presentation of the cue stimulus and the presentation of the last target equaled 
to the cue lead time plus three times the inter-target interval. Ten trials were tested for each inter-target interval, so that the whole experiment contained a total of 700 trials. The sides were equated such that the cue appeared on the right side in half of the 10 trials and on the left side in the other half. The variable in question was the direction of the apparent motion over the array with respect to the side of the cue.

Analyses. We first calculated for each inter-target interval the percentage of trials in which the apparent motion was perceived from the side of the cue stimulus. This yielded a psychometric function against the intertarget interval for each cue lead time. Using a probit analysis we then calculated the PSE.

\section{Results}

In Fig. 4, the PSE values were plotted for each subject against the cue lead time. Initial high values were followed by sustained components. The attentional effect was strongest at the shortest cue lead time $(50 \mathrm{msec}$ ) (except IM), decreased in $400 \mathrm{msec}$, and remained stable thereafter. This result again indicates the presence of an initial transient component and a sustained component.

\section{Discussion}

An important finding in this experiment was that the presence of a sustained component, which was not obvious by the temporal order task (Fig. 2). This result agrees with the previous studies (Müller \& Rabbit, 1989; Nakayama \& Mackeben, 1989) which demonstrated a sustained component of attention. Note, however, there is a tendency for every subject that the effect decreased at medium cue lead times $(400-600 \mathrm{msec})$ before reaching the sustained level.

One might wonder why the highest peaks were at shorter cue lead times compared with the data obtained in the temporal order task (see Fig. 2). This is probably dependent on how we defined the cue lead time. We defined it as the duration from the onset of the cue stimulus to the onset of the first bar. Thus, if the array of the bars was presented with the interval of $40 \mathrm{msec}$, for example, the last bar appeared $120 \mathrm{msec}$ after the first one, so that the actual cue lead time for the last target is larger than what is listed along the axis of abscissa in Fig. 4 by a margin of $120 \mathrm{msec}$. This is a probable reason why the cue lead times in Fig. 4 tended to be underestimated compared with the temporal order task (Fig. 2).

Phenomenologically, the array of visual stimuli produced an apparent motion. Apparent motion can be divided into the short-range process and the long-range process (Anstis, 1980). The separation of multiple visual stimuli used in Expt 3 (1.33 deg) is within, but close to the upper limit of, the range of short-range motion determined psychophysically (Baker \& Braddick, 1985). The stimulus configuration used in our temporal order task (Expts 1 and 2) could have produced a long-range apparent motion, but the subjects rarely reported the impression of motion perhaps because the temporal separations, either physical or psychological, were usually much smaller than the optimal range (Korte, 1915).

An additional advantage of using an array of stimuli over a pair of stimuli may come from the non-linear facilitatory nature of the motion detecting mechanism, "sequential recruitment" (Nakayama \& Silverman, 1984), in which effects of motion detectors in a particular direction are carried over multiple frames so that motion sensitivity increases relative to the two-frame case.

\section{Experiment 4: Illusory Motion in a Line Induced by Attention; Effects of Stimulus Onset}

The motion detectors respond to sequential presentation of an array of visual stimuli. Its sensitivity, however, increases if the spatial separation of the stimuli becomes smaller (Graham, 1965; Biederman-Thorson, Thorson \& Lange, 1971; Nakayama \& Tyler, 1981). For example, Biederman-Thorson et al. (1971) showed that, when two stimuli are presented in the peripheral visual field, a motion sensation is produced even with the interval of a few milliseconds, with which the stimuli may be indiscriminable if presented simultaneously; "it is only by the impression of movement that the sequence of presentation of the two dots can be successfully determined". This can be regarded as "motion hyperacuity" (Nakayama, 1985).

We therefore expected that our technique can further be improved by making the separation of stimuli even smaller. An extreme in this direction is just to present a simple line. A basic paradigm is shown in Fig. 5. A single line was presented physically at once after the cue stimulus. A strong motion sensation was perceived in the line from the side of the cue stimulus.

\section{Methods}

Subjects. Five subjects participated in this experiment; three were the authors (SM, SS, OH) and the other two subjects (YY, HI) were experienced psychologists but did not know the purpose of the experiment.

Apparatus and stimuli. The stimuli were generated and presented with the tachistoscope in a dark room. The fixation point, the cue stimulus, and the probe line $\left(52 \mathrm{~cd} / \mathrm{m}^{2}\right)$ were presented on a dark background $\left(<0.2 \mathrm{~cd} / \mathrm{m}^{2}\right)$. The fixation point $(0.05 \times 0.05 \mathrm{deg})$ and the cue stimulus $(0.05 \times 0.05 \mathrm{deg})$ were both a small spot of light. The cue stimulus was presented for each trial at one of the two possible locations (separated horizontally by $8.9 \mathrm{deg}$ ) which were $3.4 \mathrm{deg}$ above the fixation point. The probe line ( $8.9 \mathrm{deg}$ in width, $0.05 \mathrm{deg}$ in length) was presented thereafter between the two cue locations so that its terminators occluded the preceding cue stimulus completely. The observation distance was $114 \mathrm{~cm}$.

Procedure. The subject initiated each trial by pressing a key which was followed by the appearance of the fixation point. The fixation point remained on throughout the trial which the subject had to keep fixating. The cue stimulus then appeared randomly either on the right 

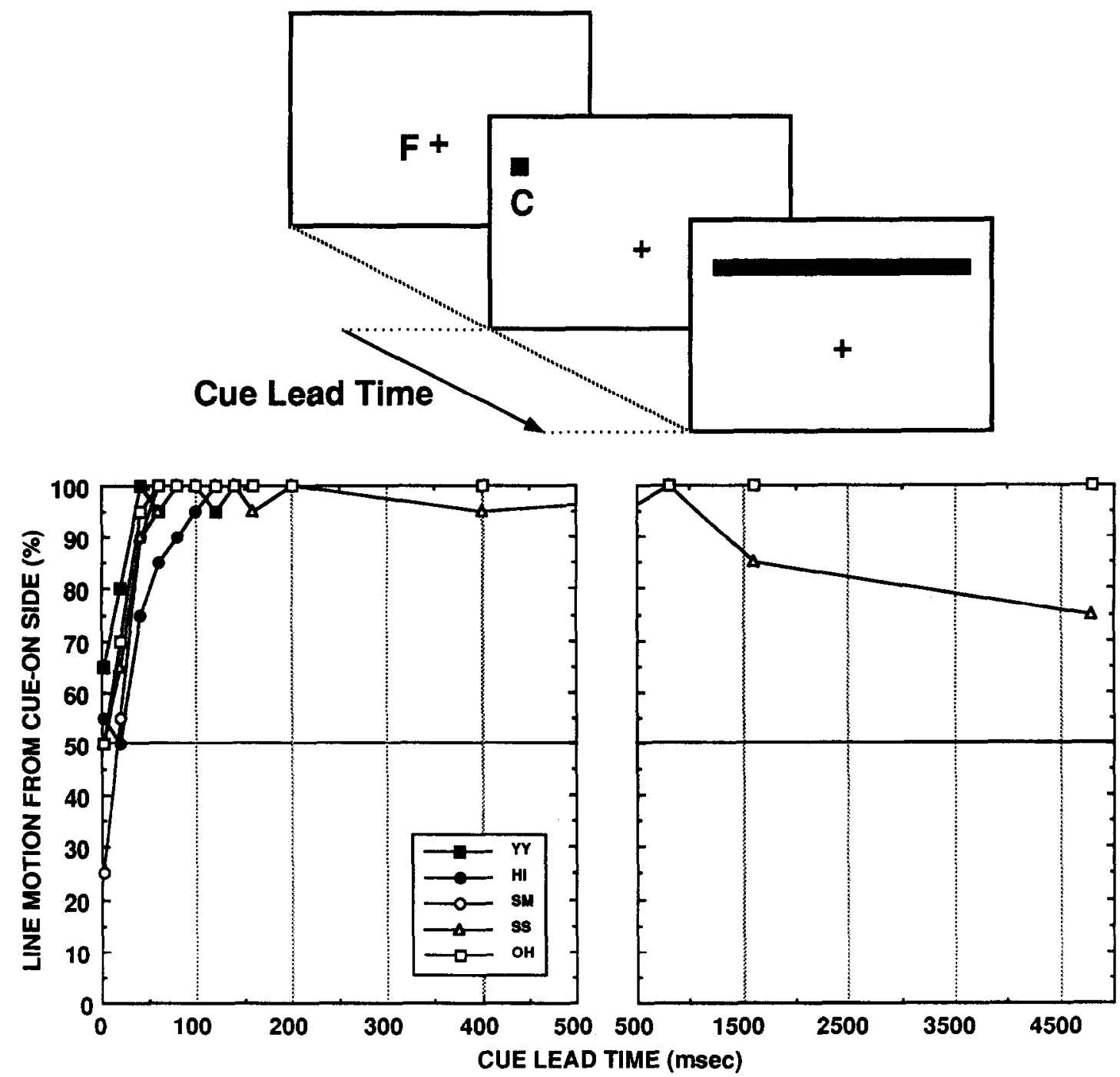

FIGURE 5. Stimulus onset induces illusory motion sensation in a line. Top: while the subject was fixating a central spot (F), another spot of light (C) came on at either one of two possible sites (right and left) in the upper visual field. After a randomized time interval (cue lead time) a line was presented at once between the two cue locations. The subject had to judge in which direction the line appeared to be drawn (two-alternative forced-choice paradigm). Bottom: the percentage of trials in which the line appeared to be drawn from the cued side (ordinate) was plotted against the cue lead time (abscissa). The graph is interrupted at $500 \mathrm{msec}$ to see both the transient and sustained components (same in the following figures). Data from five subjects are shown with different symbols. Twenty trials were obtained for each cue lead time in each subject. The chance level was $50 \%$.

or left side. After a time delay (cue lead time) the probe line came on, occluding the cue stimulus. The line was presented physically at once. The subjects task was to report in which direction the line appeared to be drawn by pressing one of the two keys (2AFC task). In a variation in this experiment, a flash stimulus of $2 \mathrm{msec}$ duration, instead of the sustained spot, was used, as the cue.

The experiment was carried out as a single block with the cue lead time randomized across trials (14 steps; ranged from 1 to $4800 \mathrm{msec}$ ). Twenty trials were tested for each cue lead time, so that each block contained a total of 280 trials. The side of the cue stimulus was randomized; overall, the cue appeared on the right side in half of the 20 trials and on the left side in the other half, for a particular value of cue lead time.

Analyses. We calculated for each cue lead time the percentage of trials in which the motion was perceived from the side of the cue stimulus, and plotted it against the cue lead time.

\section{Results}

Figure 5 shows the results obtained from five subjects. The motion sensation in the line started to build up at a cue lead time of $20 \mathrm{msec}$ and reached a plateau at around $100 \mathrm{msec}$. The line was seen as if it had been triggered out of the cue stimulus. When the cue lead time was short $(<50 \mathrm{msec})$, the presence of the cue stimulus was often not recognized, yet the motion in the line can be clearly seen. For most subjects, the motion sensation remained complete up to the longest cue lead time $(4.8 \mathrm{sec})$. Subjectively, however, the sensation was strongest at the cue lead times between 100 and $200 \mathrm{mscc}$, as suggested typically by the data of SS.

When a flash stimulus (duration: $2 \mathrm{msec}$ ), instead of the sustained spot, was used as the cue stimulus, a 

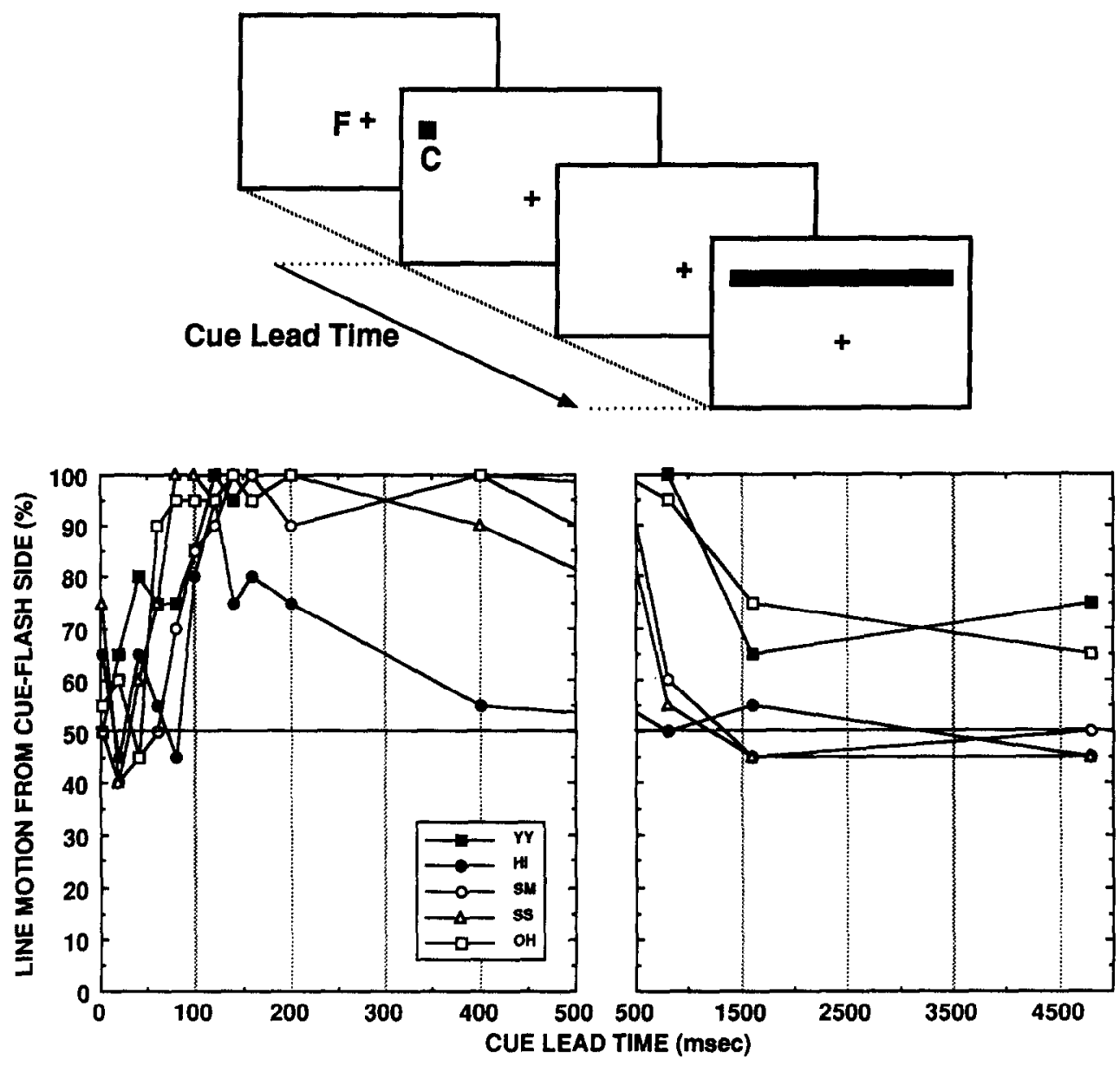

FIGURE 6. Transient effects of illusory motion induced by stimulus flash. The same experiment as in Fig. 5, except that the cue spot of light was flashed briefly ( $2 \mathrm{msec}$ ); the probe line came on when the cue stimulus was no longer present. Data from five subjects are shown with different symbols.

transient effect became apparent (Fig. 6). The effects were more variable with short cue lead times, peaked after $100 \mathrm{msec}$, and returned close to the chance level after $1 \mathrm{sec}$.

\section{Discussion}

A comparison between this line motion task (Fig. 5) and the temporal order task (Fig. 2) shows common features, even though the target parameters are different. The maximum effects occurred around the cue lead time of $100 \mathrm{msec}$ in both experiments. Furthermore, there seems to be a correlation among individual subjects: at short cue lead times in both of the experiments the effects appear stronger with earlier onsets in $\mathrm{YY}$ and $\mathrm{OH}$ compared with HI and SM. A similar tendency was present when a short flash was used of the visual cue. The difference does not seem dependent on experience, because $\mathrm{OH}$ and SM are the authors and far more experienced than the other subjects who were unfamiliar with this task.

A significant difference, however, was observed between the temporal order task and the line motion task at longer cue lead times. In the line motion task with a sustained cue (Fig. 5) the motion remained nearly perfect (in terms of probability), whereas the temporal asynchrony became unclear in the temporal order task (Fig. 2). The latter effect is rather similar to the transi- ent effect obtained using a short flash as the visual cue (Fig. 6). These results, together with the subjective reports that the impression of motion was strongest at around $100 \mathrm{msec}$, suggest presence of the transient component of attention which is separable from the sustained component, as suggested in the previous studies (Nakayama \& Mackeben, 1989).

A further support for this notion comes from our recent report which compared the stimulus-induced and voluntary attention (Hikosaka, Miyauchi \& Shimojo, 1993). If the subject is instructed to pay attention voluntarily to the uncued side (unlike the experiments in this study), the sustained effect can be reversed. The initial phasic component $(<300 \mathrm{msec})$, however, remains unchanged, overcoming the voluntary efforts. The line motion task seems sensitive enough to detect and isolate the sustained component of attention which is weaker and subject to volitional control.

\section{Experiment 5: Illusory Motion in a Line Induced by Attention; Effects of Stimulus Offset}

Experiment 2, using the temporal order task, has suggested that visual offset, in addition to visual onset, is effective in inducing local facilitatory effects (passive attention) and that the effect is transient and overcome by the sustained effect induced by the remaining stimulus. A new approach to this question, using the line 
motion method, is expected to yield a more reliable set of data, in view of the successful results obtained for the visual onset-induced attention (Expt 4). Moreover, the effect of cue offset on line motion would be a further test for our hypothesis that both the illusory temporal order and the line motion phenomena are based on the same mechanisms of spatial attention.

\section{Methods}

Subjects, apparatus, and stimuli were the same as those used in Expt 4.

Procedure. The procedure was the same as Expt 4, except for presentation of the cue stimuli (Fig. 7). Each trial started with the presentation of the fixation point and two cue stimuli. One of the two cue stimuli then went off randomly either on the right or left side. This was followed with a cue lead time $(1-4800 \mathrm{msec}$, randomized) by presentation (physically simultaneous) of the probe line. The subjects task was to report in which direction the line appeared to be drawn by pressing one of the two response keys (2AFC task). The configuration and analyses of the experiment were the same as Expt 4.

\section{Results}

The results from the five subjects were similar to each other (Fig. 7). The effect of the offset of the cue stimulus was not clear until the cue lead time became about $100 \mathrm{msec}$. At cue lead times between 100 and $300 \mathrm{msec}$, the motion sensation was perceived more often from the cue-off side. The direction of perceived motion was then reversed, now from the side where a cue stimulus remained. Its direction was unchanged at longer cue lead times.

\section{Discussion}

The data suggest that visual offset induces attention transiently but soon gives way and is overtaken by another focus of attention produced by a remaining
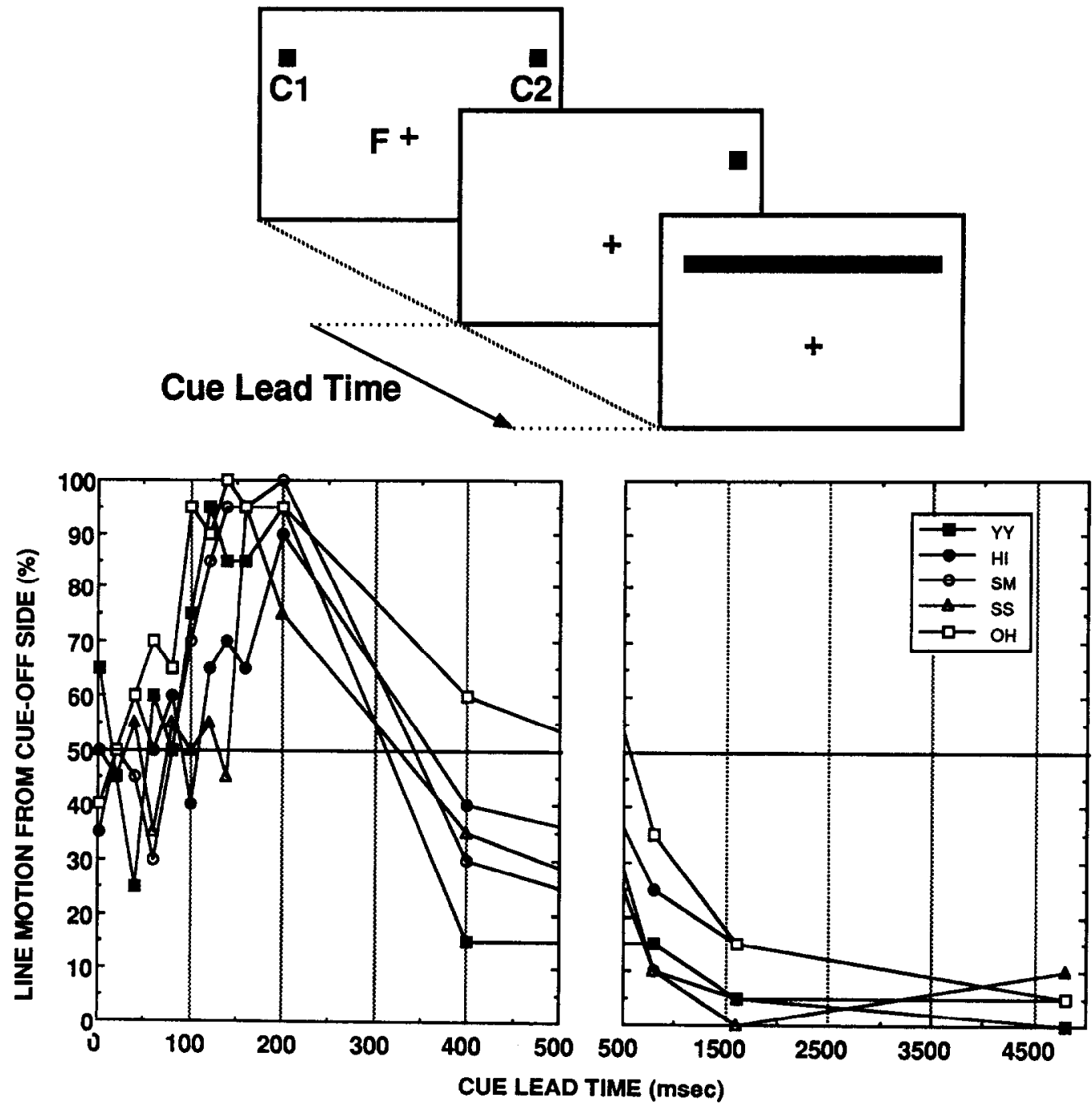

FIGURE 7. Stimulus offset induces illusory motion sensation in a line. Top: the trial started with two spots (cue stimuli; C.1 and C.2) on, as in Fig. 3. While the subject was fixating, one of the cue stimuli went off. After a randomized time interval (cue lead time) a probe line was presented at once between the cue locations. The subject had to judge in which direction the line appeared to be drawn. Bottom: the percentage of trials in which the line appeared to be drawn from the cue-off side (ordinate) was plotted against the cue lead time (abscissa). Data from five subjects are shown with different symbols. Twenty trials were obtained for each cue lead time in each subject. With shorter cue lead times the line tended to appear to be drawn from the side where the cue went off, but reversed its direction at around $400 \mathrm{msec}$. 
stimulus. This result, based on the line motion method, is qualitatively similar to the one obtained in Expt 2 (Fig. 3) which was based on the temporal order task. Among individual subjects is seen some correlation. For example, the effect of the cue offset was strongest in $\mathrm{OH}$ in both of the tasks. Similar correlations were already noted for the visual onset-induced attention; between Expt 1 and Expt 4. These comparisons, taken together, further suggest that what is revealed in the line motion task is the temporal asynchrony of visual information processing, namely the effect of attention.

The transient nature of cue off-effect is further emphasized if we compare the result of this experiment and that of Expt 4 (cue on). In both of the experiments one cue stimulus remained after the visual transient, yet the initial effects were completely opposite and depended on which side the transient change occurred. The effects were then replaced by the effects of the remaining cue stimulus. These profiles are all understandable when we consider both transient and sustained components of attention. In the cue-on case, the initial transient activation by the onset of cue is followed by the sustained activation on the same side. In the cue-off case, the initial transient activation by the offset of cue is followed by the sustained activation on the other side.

\section{Attention Includes Binocular Mechanisms}

The results of Expts 4 and 5 suggest that the local facilitatory effects induced by visual onsets or offsets occur before the presumed motion detectors. How early in the visual processing could the modulation be? One possibility is that it occurs before the binocular interaction; in the lateral geniculate or even in the retina. If so, the illusory motion sensation would be completely abolished when the cue stimulus and the probe line are presented to different eyes.

Experiment 6 was designed to address this issue. When the cue and the line were presented dichoptically (the cue to one eye and then the line to the other eye), phenomenologically the same line motion was perceived. Moreover, the spatio-temporal profiles of the motion effect were quite similar between the dichoptic and the monocular control.

\section{Experiment 6: Dichoptic Presentation of the Cue and the Line Probe}

\section{Methods}

Subjects. Four subjects participated in this experiment; two of the authors (SM, OH), one experienced psychologist (IM), and one naive subject (MT).

Apparatus and stimuli. A microcomputer (NEC PC9801RA) was used for stimulus presentation and the control of experiments. Its frame rate was $60 \mathrm{~Hz}$. On a dark background $\left(<0.2 \mathrm{~cd} / \mathrm{m}^{2}\right)$ of the computer monitor screen were presented a series of stereo half images, and the subject was viewing these stereograms through a mirror haploscope. First, a fusible open white rectangle was presented to facilitate stable binocular fusion (width, $7.5 \mathrm{deg}$; height, $11.5 \mathrm{deg}$; see Fig. 8). A fixation point $(0.12 \times 0.12 \mathrm{deg})$ was also presented binocularly at the lower central part of each rectangle. Then a cue stimulus (a white spot of light, $0.3 \times 0.3 \mathrm{deg}$ ) and a probe line (white, length $6.2 \mathrm{deg}$; width $0.3 \mathrm{deg}$ ) were presented in this sequential order. The luminance of these stimuli was $61 \mathrm{~cd} / \mathrm{m}^{2}$. There were two possible cue locations (right and left) in the rectangular fusion frame. The probe line was presented as connecting the two cue locations. The cue stimulus as well as the probe line was presented always monocularly (either to the same eye, or to the opposite eyes), while the side was randomized across trials. By dichoptic viewing the subject perceived that there was a single rectangle within which a cue stimulus appeared on the right or left side and finally the probe line appeared whose terminator occluded the cue stimulus. The angular distance between the cue locations was $6.0 \mathrm{deg}$; the test stimuli (cue and line) were $4.5 \mathrm{deg}$ above the fixation point. The observation distance was $57 \mathrm{~cm}$.

Procedure. The task of the subject was the same as in Expt 4: while the subject was fixating, a cue stimulus appeared and then after a cue lead time the probe line was presented physically at once; and the subject reported in which direction the line appeared to be drawn (2AFC task).

There were four combinations in terms of the sides of the eyes stimulated; two monoptic conditions (both cue and line, to the left or right eye, respectively) and two dichoptic conditions (cue to the left eye/line to the right eye, and cue to the right eye/line to the left eye). The experiment was carried out as a single block with these stimulus combinations $(\times 4)$, the side of the cue stimulus $(\times 2)$, and the cue lead time (11 steps; ranged from 0 to $3400 \mathrm{msec}$ ) randomized across trials with equal probabilities. For each of the monoptic and dichoptic conditions, the cue appeared on the right side in half of the 20 trials and on the left side in the other half.

Analyses. We compared the data between the monoptic conditions and the dichoptic conditions. We calculated the percentage of trials in which the motion was perceived from the side of the cue stimulus for each group of data for each cue lead time, and plotted it against the cue lead time.

\section{Results}

Figure 8 compares the time courses of the illusory motion sensation under the two viewing conditions: monoptic and dichoptic. The data clearly indicate that the illusory motion was perceived under the dichoptic viewing condition as well. Its time course was similar to the one obtained by monoptic viewing (this experiment) or binocular viewing (Expt 4). The subjects reported that the monoptic and dichoptic views could not be subjectively differentiated.

\section{Discussion}

The data suggest that the site of attentional modulation is after interaction of binocular signals. Because the binocular interaction first occurs in V1 (area 17) 
88828 영요웅
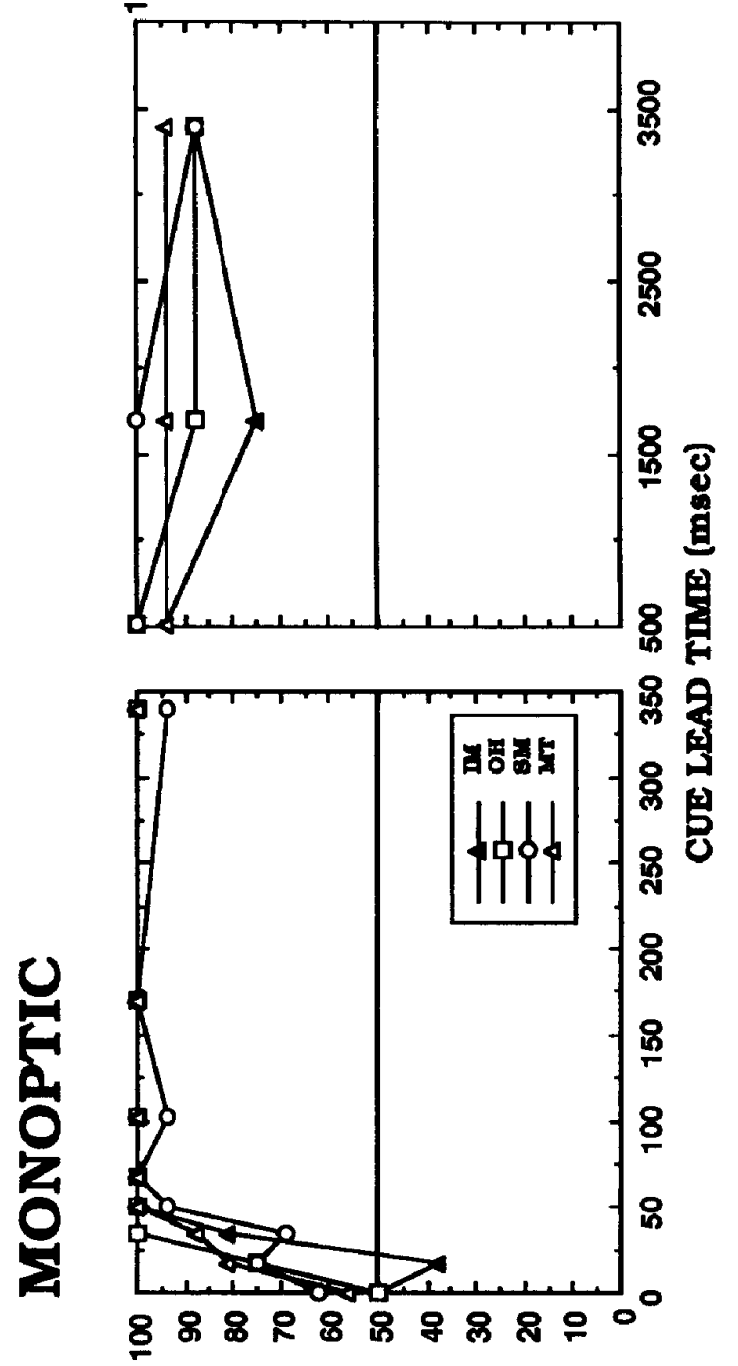

(\%) aus no-sino woys Nolnon anrT

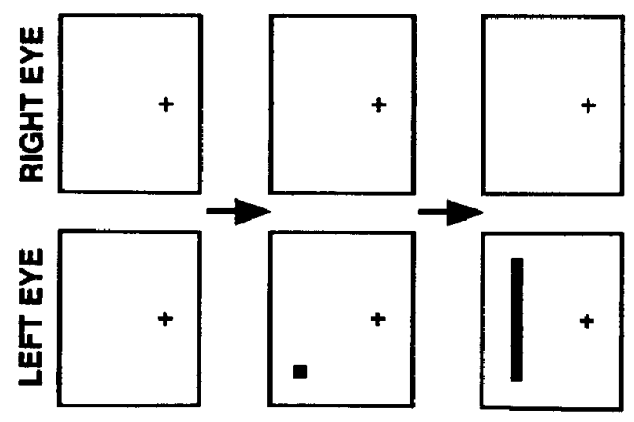

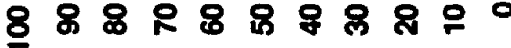

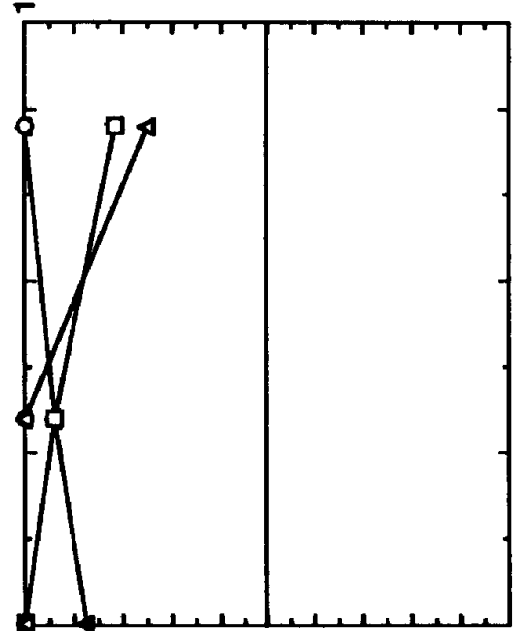

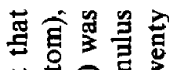

品 कि

3ै

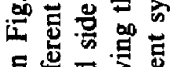

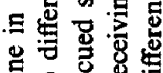

8 5 0

సึ

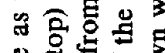

岁宁

8 8

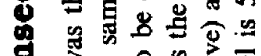

国

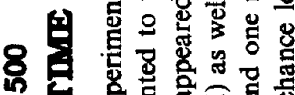

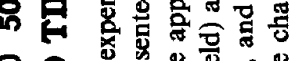

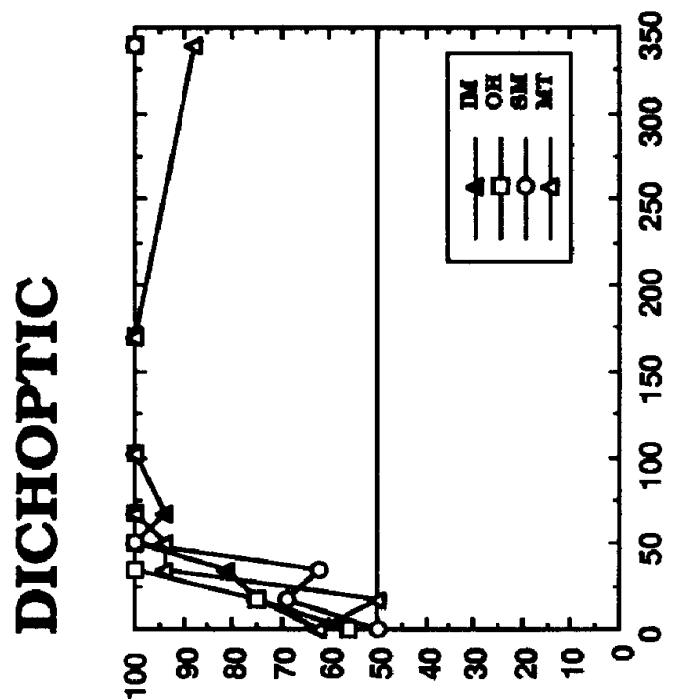

(\%) aars NO-anJ พOYA NOILON aNIT

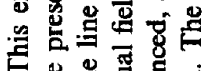

8 勇

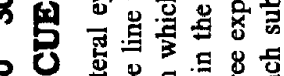

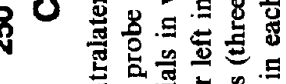

을

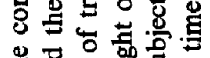

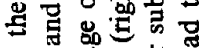

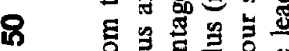

8 品

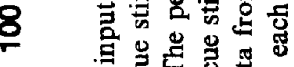

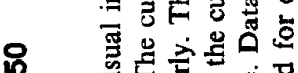

要F

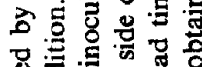

8 远

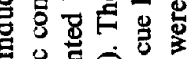

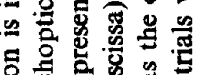

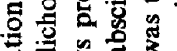

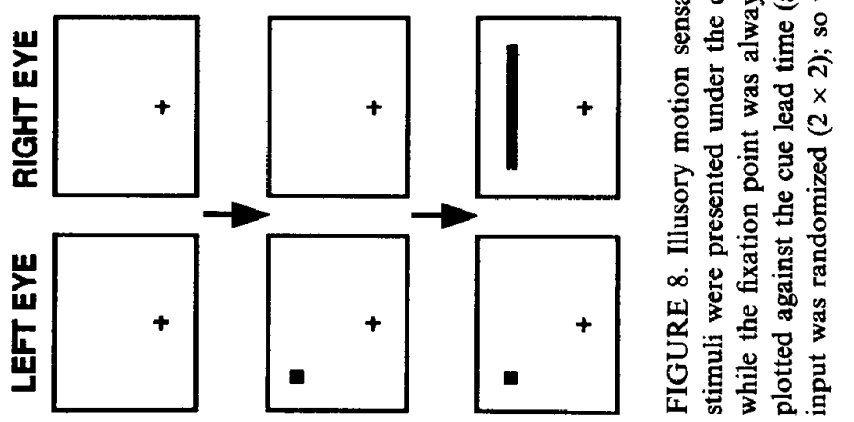


along the geniculo-cortical system (Hubel \& Wiesel, 1962), the attentional effect would be produced after V1, not in the retina or the lateral geniculate nucleus. *

This idea is in agreement with most of the evoked potential studies in humans. The evoked potential to a sensory stimulus (visual, auditory, or tactile) is enhanced when the subject attends to it (Hillyard, 1985). The enhancement, however, occurs only for the later components of the evoked potential which are considered to reflect cortical, rather than peripheral, processing (but see Eason, 1981).

The cortical hypothesis of attention is yet not the only possibility, however, if we consider the extrageniculate pathway. Binocular interaction occurs already within the superior colliculus, the direct target of retinal ganglion cells (Cynader \& Berman, 1972), although it might be produced by binocular cortical signals fed back to the colliculus.

\section{Object-Bound Attention}

In the examples we have examined so far, attention was produced by a single event of either stimulus onset or offset at a particular retinotopic location. We now extend our analysis to a more complicated and global spatio-temporal situation. Suppose an object jumps from one place to another; there are two distinct visual events, onset and offset, at different retinal locations. The experiments described above might suggest that there appear two foci of attention at the two locations. Are these happening totally independently, or interacting such that the focus of attention follows the jumping object?

Experiment 7: Offset-Induced Attention may be Suppressed by Onset-Induced Attention Elsewhere: when the Cue Undergoes Apparent Motion

In this experiment we compared the visual off-induced attention in two situations: (1) when the visual stimulus simply disappeared (stimulus-off condition), and (2) when the visual stimulus appear to jump to another location (stimulus-step condition). The initial local events were identical (i.e. offset of a visual stimulus), but perceptual outcomes were completely different. Our question was whether the perceptual difference is correlated with the difference in spatial attention, which in turn should supposedly be reflected in line motion.

\section{Methods}

Subjects. Three subjects (the authors) participated in this experiment.

Apparatus and stimuli. A microcomputer (NEC PC-9801RA) was used for stimulus presentation and the control of experiments. The fixation point, the stimuli,

*There is certainly a remote possibility that the actual locus of line motion itself is more periphery and the dichoptically presented cue affects through cortico-geniculate feedback pathways (Long, 1979). But even in this case, the neurological level of binocular convergence is critically involved for the occurrence of line motion effects. and the probe line $\left(61 \mathrm{~cd} / \mathrm{m}^{2}\right)$ were presented on a dark background $\left(<0.2 \mathrm{~cd} / \mathrm{m}^{2}\right)$. The fixation point and the stimuli were small spots of light $(0.15 \times 0.15 \mathrm{deg})$. The stimuli were located at four corners of an invisible rectangle surrounding the fixation point (Fig. 9, top); the angular distance was $1.1 \mathrm{deg}$ between the adjacent stimuli and was $1.5 \mathrm{deg}$ between the fixation point and the stimuli. The probe line connected either the upper or lower pair of the stimuli (width: $0.04 \mathrm{deg}$ ). The observation distance was $57 \mathrm{~cm}$.

Procedure. The subject initiated each trial by pressing a key which was followed by the appearance of the fixation point and three of the four stimuli; one of the stimulus positions was vacant. The subject had to keep fixating at the fixation point throughout the trial. After $1 \mathrm{sec}$, one of the following two events occurred in a random manner. In the first case, the stimulus that was on the same side as the vacant stimulus position disappeared, leaving two stimuli on the other side (stimulus offset). In the second case, the stimulus similarly disappeared but at the same time another stimulus appeared at the previously vacant position (stimulus step); this yielded a compelling perception of apparent motion that a single stimulus stepped from one place to another. The sequence of stimuli was arranged so that the apparent step motion was always vertical (either upward or downward). In both of the stimulus off case and the stimulus step case, after a time delay (cue lead time), the probe line was presented between the horizontal pair of stimuli which included the one that disappeared (see the upper half of Fig. 9). The subjects task was to report in which direction the probe line appeared to be drawn (2AFC task). As in the preceding experiments, the subject was required not to pay attention voluntarily to specific locations or specific stimulus features.

The experiment was carried out as a single block in which three parameters were randomized: the mode of stimulus (off or step), location of the initial vacant position, and cue lead time $(2 \times 4 \times 12)$. Five trials were tested for each condition, so that the block contained a total of 480 trials.

Analyses. We calculated for each condition (off and step) at each cue lead time the percentage of trials in which the motion was perceived from the side where the stimulus disappeared, and plotted it against the cue lead time. Four conditions of initial vacant position were pooled for the data analyses.

\section{Results}

For each subject the results are compared between the stimulus-off condition and the stimulus-step condition (Fig. 9, bottom). They were clearly different and the difference was consistent across the subjects.

The results for the stimulus-off condition were in general agreement with the results of Expt 5 (effects of stimulus offset). The result of this experiment again suggests that attention was at first drawn to the location where the stimulus disappeared (close to $100 \%$ ), but was then reversed to the other side where another 

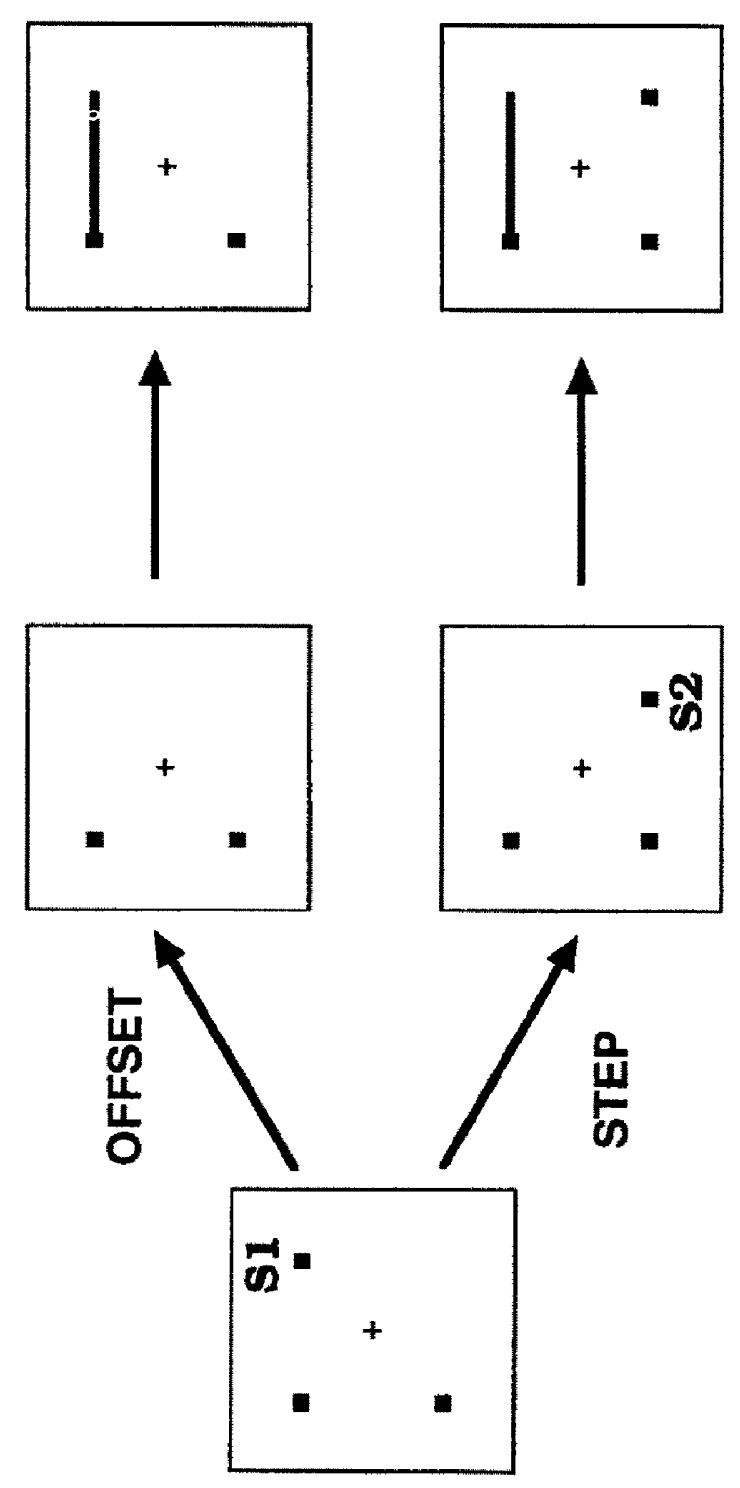

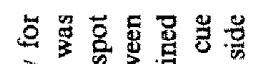

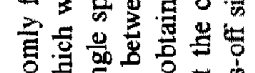

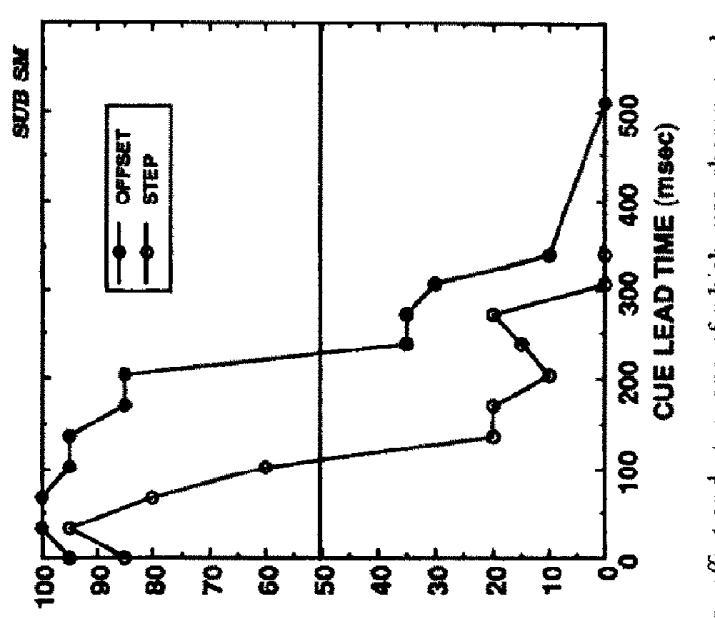

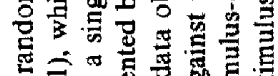

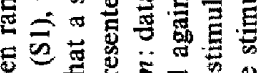

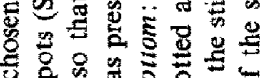

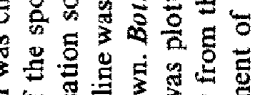
들

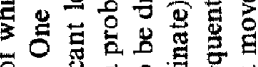

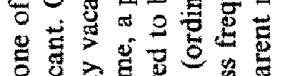

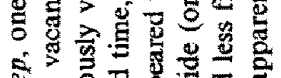

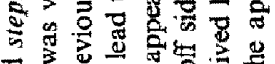

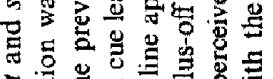

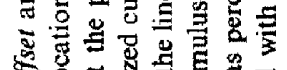

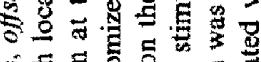

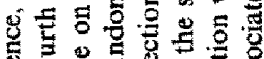

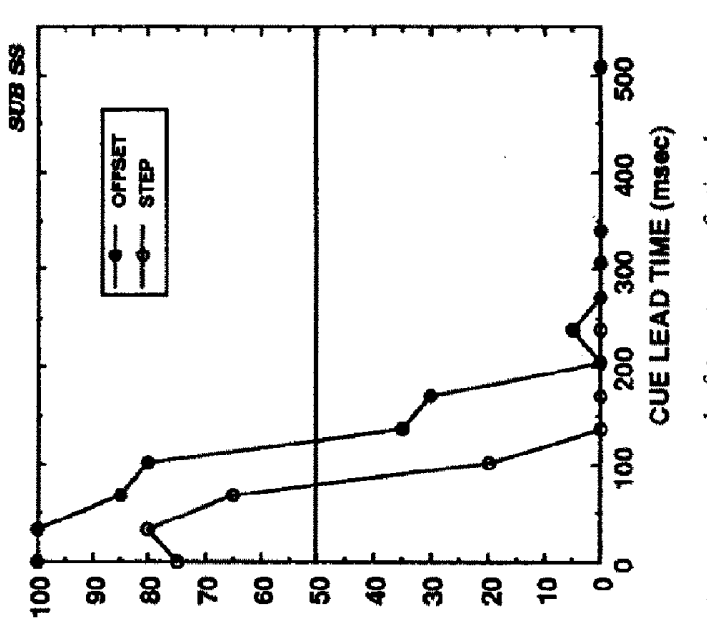

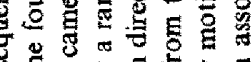

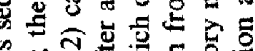

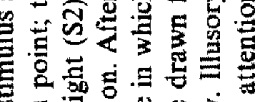
क

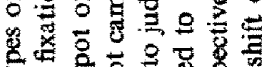

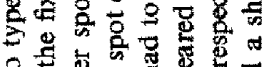

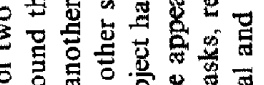
政

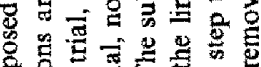

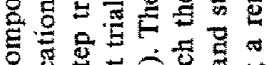

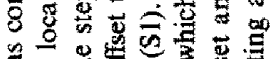

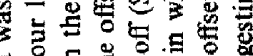

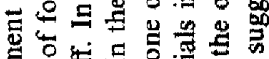

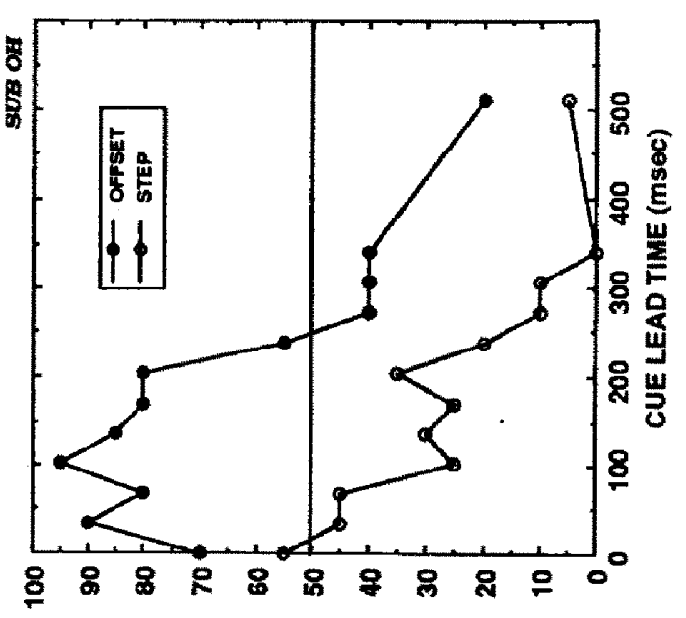

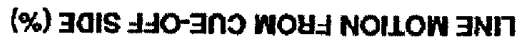

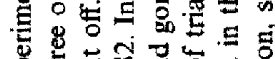
ชั

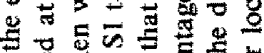

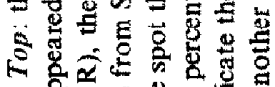
को वे.

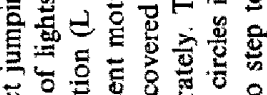
5)

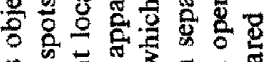

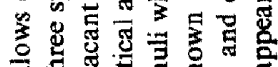

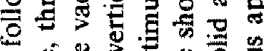

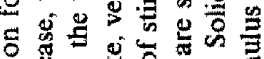

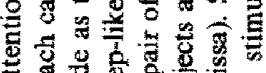

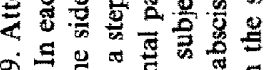

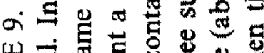

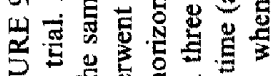

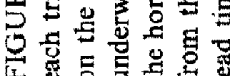



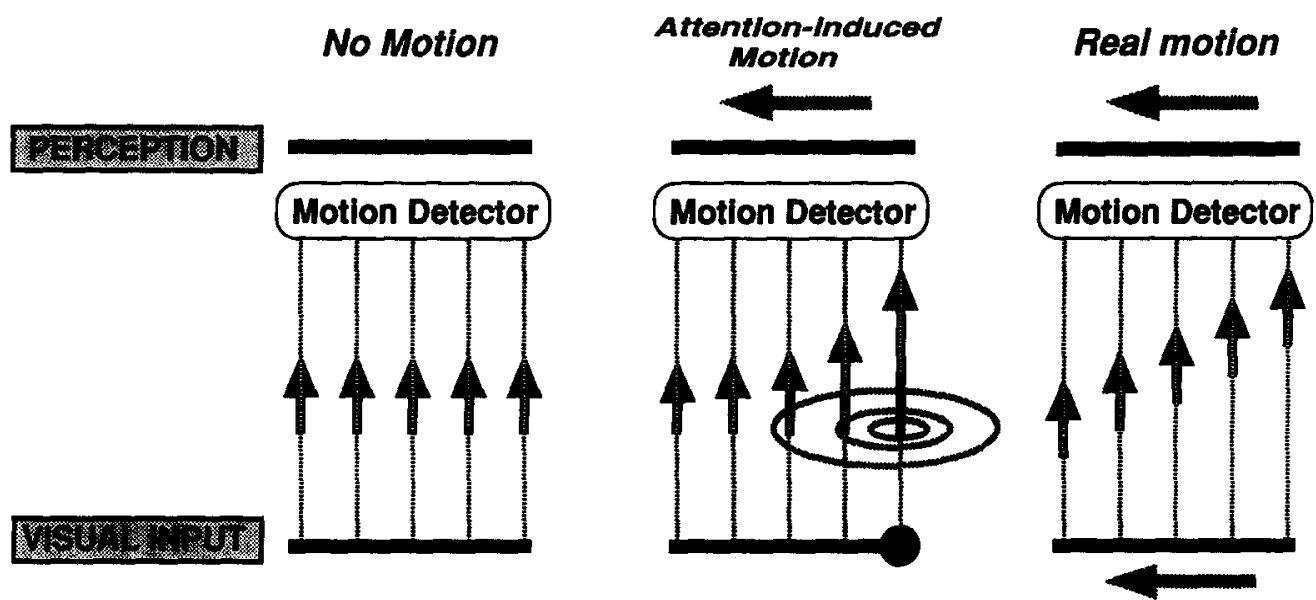

FIGURE 10. Hypothetical neural mechanism underlying the stimulus-induced illusory motion. Since attention facilitates local visual information processing before the signals reach the motion detectors, it creates virtual time delays across neighboring locations which mimic real motion in effect on the detectors.

stimulus remained (close to $0 \%$ ). In two of the subjects (SM and $\mathrm{OH}$ ) the transition occurred gradually crossing the chance level at around $250 \mathrm{msec}$; the other subject (SS) showed an earlier and faster transition.*

In the stimulus-step condition, it was less likely that the motion in the line was perceived from the stimulusoff side, suggesting that attention could not be held at the stimulus-off location. This was true for every subject at all cue lead times. There may be some tendency at short cue lead times $(0-100 \mathrm{msec})$ that attention was shifted to the stimulus-off side, but this was quickly replaced by the attention shifted to the opposite side.

\section{Discussion}

The only physical difference between the stimulus-off condition and the stimulus-step condition was whether or not a spot appeared at another location after the disappearance. Perceptually, of course, these two stimulus configurations produce different impressions: off and apparent step motion. One might argue that the effect on attention is based on the difference in this perceptual judgment. However, the difference started to occur at the short cue lead times $(0-50 \mathrm{msec})$. It would be difficult to imagine how the perceptual judgment could modulate the focus of attention at such early stages of visual processing. Further, the subjects were encouraged not to pay attention to the difference in the stimulus configurations; and even if forced to pay attention, the difference tended to remain unnoticed in the course of the repetition of the task trials.

These results, on the other hand, raise many questions. Does the stimulus-onset-induced attention always dominate the stimulus-offset-induced attention, so that the former always vetoes the latter? What is the

\footnotetext{
*A difference between the present results in the stimulus off condition and Expt 5 was that the shift of attention to the stimulus-off side was already present at zero cue lead time. This may be due to the fact that in the present experiment the side of stimulus on and off was pre-determined and obvious even in frame No. 1 of the stimulus sequence, unlike in Expt 5, thus the subjects expectation could have easily been developed (see Fig. 9).
}

time-course of the interaction? What happens if these two types of attention are produced asynchronously? These questions may be answered psychophysically by changing the stimulus parameters. A final important question is: what is the underlying neural mechanism? This question may not be answered easily, however, because what we are seeking is not the interaction between sensory processes but the interaction between attentional processes, each of which is not visible independently of sensory processes.

\section{GENERAL DISCUSSION}

Attention-induced local facilitation is detected as a motion

Attention may be defined as the state of mind in which a limited portion of sensory processing is temporarily facilitated while the other portion may be suppressed. The local facilitatory effect which we observed using the temporal order method or the line motion method would then reflect attention which is produced by the onset or offset of a visual stimulus. Although the subject was non-attentive at the start of each task trial, his mind was brought into the attentive state passively by the cue stimulus. To examine such a bottom-up effect on attention, it was crucial to ask the subject not to pay attention voluntarily to the stimuli. Otherwise, the other aspect of attention-top-down, voluntary aspect--would have confounded our results [in a separate study (Hikosaka et al., 1993) we studied the top-down aspect and its relation to the bottom-up aspect].

A main message of the present study is that the gradient of visual spatial attention can be revealed by an illusory "drawing" or a motion of a probe line. The direction of the illusory motion is from the focus of attention outward, just as water runs downstream. Attention is a dynamic process which grows and fades away, but the probe line visualizes the instantaneous gradient of attention as an illusory motion.

The basic principle of, and the hypothetical mechanism underlying this line motion method is schematized in Fig. 10. We perceive visual motion when the 
motion detecting mechanism in the brain is activated (Nakayama, 1985; Newsome, Britten, Movshon \& Shadlen, 1989). The motion detector, wherever it is located in the central nervous system, is activated when visual inputs are fed into it sequentially in one direction. This usually occurs when a visual object actually moves in space so that the retina receives. sequential visual inputs. In this case, the motion detector detects the real motion faithfully. However, the motion detector may be deceived by non-physical factors which influence the speed of signal transmission before the visual signals reach the motion detector. [A good analogy to this would be the Pulfrich depth effect (Rogers \& Anstis, 1972) where an illusory binocular disparity caused by an intensity difference between the eyes produces depth effect at some central level of visual processing.] As we have already discussed, attention is characterized by the process by which the speed, as well as the amount, of signal transmission is selectively facilitated while others may be inhibited (Kahneman \& Treisman, 1984; Johnston \& Dark, 1982). Further, the effect of attention is considered to be a gradient, decreasing from its center to periphery (Sagi \& Julesz, 1986; Downing, 1988; Mangun \& Hillyard, 1988; Kröse \& Julesz, 1989; LaBerge \& Brown, 1989). When a visual stimulus (a line) appears at once within the field of attention, the visual input that is closest to the center of attention would reach the motion detector first, followed by the input from the adjacent portion and then the next adjacent portion, and so on. Thus, the motion detector would be completely deceived and send out a neural message that motion has occurred.

The illusory motion appeared smoothly spanning the whole length of the probe line. This observation further suggests that the magnitude of attention is characterized by a gradient (see above), rather than a spotlight. We recently confirmed this hypothesis with the same line motion technique, but using a short line as a probe (Miyauchi, Hikosaka \& Shimojo, 1992).

The motion detector is used here as a tool for detecting the asynchrony of visual inputs. In the temporal order task detecting mechanisms should initially function at two different retinal locations, and then a higher mechanism should determine the temporal order between them, thus allowing several opportunities for noises to contaminate. In contrast, in the line motion task the local temporal order itself is directly detected by the motion detector so that it could be less noisy in the line motion task. Indeed, the motion detector is known to be extremely sensitive to a minimal spatial offset occurring in a minimal time period (Biederman-Thorson et al., 1971). An additional advantage of recruiting the motion mechanism comes from its non-linear facilitatory nature in that it is more responsive to multiple, sequential stimuli (Nakayama \& Silverman, 1984).

\section{Attention has influence on relatively early stages in visual information processing}

The discussion above leads to an intriguing implication as to the mechanism of visual attention. As is obvious from the scheme in Fig. 10, the facilitatory effect of attention must, at least partly, occur before the motion detector. A well known motion-selective area in the brain is the area MT (V5) (Van Essen, Maunsell \& Bixby, 1981; Zeki, 1974). Responses of neurons in the area MT of the monkey are well correlated with perception of motion (Newsome, Mikami \& Wurtz, 1986). Electrical stimulation of the MT affect motion perception as expected from the responsiveness of neurons in the vicinity (Newsome et al., 1989). It is suggested therefore that the site of the attentional effect is possibly before MT.

This idea is supported by the differences in receptive field sizes between visual cortical areas. As illustrated in Fig. 10, the attentional effects would be heterogeneous such that neurons carrying the visual signal close to the cue stimulus transmit the signal faster than neurons carrying more distant signals. For this to occur, the receptive fields of such attention-modulated neurons must be significantly smaller than the area occupied by the probe line. The probe line in our experiments was presented at 3-6 deg from the fixation point. The sizes of receptive fields at such eccentricities are 3-6 deg in MT; those in V1 (primary visual cortex) are $1 \mathrm{deg}$ or less (Mikami, Newsome \& Wurtz, 1986). MT neurons thus seem unable to tell such a fine gradient of signal processing. Thus, the effect of attention would at least involve neurons located somewhere upstream to MT. Although there exist motion-sensitive neurons in the hierarchically higher cortical areas such as MST and STS (Ungerleider \& Desimone, 1986; Bruce, Desimone \& Gross, 1981; Tanaka \& Saito, 1989; Saito, Yukie, Tanaka, Hikosaka, Fukada \& Iwai, 1986; Sakata, Shibutani, Ito \& Tsurugai, 1986), their receptive fields generally are larger than in MT.

The possible neural locus of the attentional modulation was further narrowed down by our dichoptic viewing experiment (Expt 6) which showed that the cue to one eye induced illusory line motion in the other eye. This would be expected if the attention-modulated neurons receive signals form both eyes. All visual cortical areas including V1 contain binocular neurons, whereas few such cells are found in the lateral geniculate nucleus (Hubel \& Wiesel, 1961). A simple hypothesis emerging from this consideration is that the attentional modulation occurs after V1. The results of the present study altogether suggest that the likely site of spatial attention is somewhere between V1 and MT, though this does not necessarily exclude the possibility of some higher areas to be involved as well.

This view is in line with the data obtained by physiological and neuropsychological studies. In a series of behavioral-physiological studies using trained monkeys, Wurtz and his colleagues have demonstrated that visual attention works differentially at different cortical and subcortical areas (Wurtz, Goldberg \& Robinson, 1980). For example, visual responses of neurons in the posterior parietal cortex are enhanced when the monkey makes a saccade to the stimulus (Robinson, Goldberg \& Stanton, 1978). Furthermore, their visual responses are enhanced 
when the monkey just pays attention to the stimulus without making a saccade to it. This type of modification was taken to be a physiological mechanism underlying attention. Posner, Walker, Friedrich and Rafal (1984) showed that patients with lesions in the parietal cortex had difficulty in disengaging attention; engagement of attention was not disrupted. They also suggested that the site of attentional modification is not in the parietal cortex but somewhere in its upstream input pathways. In contrast to the parietal cortical neurons, visual responses of V1 neurons are seldom enhanced when the monkey makes a saccade to the stimulus (Wurtz \& Mohler, 1976).

Our conclusion supports the psychological studies showing that the sensitivity of visual perception is affected by precueing (Bashinski \& Bacharach, 1980; Downing, 1988). Downing (1988) demonstrated that the sensitivity is maximally enhanced at the cue location in a luminance detection task as well as in a form discrimination task. Attention was thus thought to affect perceptual processing at relatively early levels.

Our hypothesis also agrees with the recent findings of evoked potential studies in humans (Hillyard, 1985). Although some of the earlier studies suggested the pre-cortical modulation of sensory signals by attention (Eason, Harter \& White, 1969; Hernandez-Peon, 1967), recent studies show that the attention-induced enhancement of sensory evoked potentials occurs mostly after the presumed first cortical events (Hillyard \& Picton, 1987; Desmedt \& Robertson, 1977).

\section{Possible roles of the extrageniculate subcortical structures}

Alternatively to these "cortical" evidence, subcortical areas may be the site of the attentional effect. The extrageniculate system (superior colliculus and pulvinar) and the basal ganglia are the two candidates.

The superior colliculus receives inputs from the retinae directly and its outputs are transmitted via the pulvinar to the visual cortical areas including the area MT (Rodman, Gross \& Albright 1990; Girard, Salin \& Bullier, 1992). Therefore the superior colliculus may well be the site where the facilitatory effects of attention are produced (see Fig. 10). In fact, the visual responses in the superficial layer of the monkey superior colliculus are enhanced when the monkey attempts to make a saccade to the visual stimulus (Goldberg \& Wurtz, 1972) or when the monkey attended to the stimulus to perform a match-to-sample paradigm (Gattas \& Desimone, 1991).

This idea might be supported by the well-known role of the superior colliculus in behavioral orienting. Visual onsets or offsets, which we used in the present study, would strongly evoke behavioral orienting, especially saccadic eye movement. The superior colliculus is indeed a key structure for the initiation of saccadic eye movements (Sparks \& Hartwich-Young, 1989); output cells in the intermediate layer, receiving a wide range of sensory-motor inputs, convey transient, burst signals to the brainstem saccade generators. In view of the close functional correlation between attention and eye movement, it is natural to wonder if the stimulus-induced attention involves the superior colliculus.

The pulvinar also has been implicated to be related to visual attention (Robinson \& McClurkin, 1989; LaBerge \& Buchsbaum, 1990). Pulvinar neurons show the saccadic enhancement of visual response. The reversible blockade of the pulvinar on one side by injection of a GABA agonist leads to severe hemineglect. The pulvinar is in an appropriate position to communicate with the visual cortical areas with mutual fiber connections.

Unilateral dysfunction of the basal ganglia is known to produce hemineglect-contralateral inattention (Ljungberg \& Ungersteadt, 1976). The saccadic enhancement of visual response, as seen in the superior colliculus, have also been observed in the substantia nigra pars reticulata (Hikosaka \& Wurtz, 1983) and the caudate nucleus (Hikosaka, Sakamoto \& Usui, 1989), both constituting the system of the basal ganglia. With its inhibitory connection to the superior colliculus, the substantia nigra might participate in attentional selection.

\section{Attention may follow a moving object}

We have shown that both onset and offset of visual stimulus draw attention, although the offset-induced attention develops more slowly (Fig. 7). The onset of a visual stimulus is particularly powerful in attracting attention. Using a reaction time task in which the subject detect the presence or absence of the prespecified target letter among irrelevant letters, Yantis and Jonides (1984) showed that a newly appearing letter pops out irrespective of display size, measured as shortening of reaction time, while a letter formed by removing line segments from a preexisting non-letter figure required serial search. They concluded that the onset transients have absolute priority over offset transients in inducing attention. The results of our experiments may seem at variance with these studies, but there are important differences in stimulus arrangements. We examined the effect of stimulus offset independently with onset, whereas onset and offset occurred at the same time in the Yantis and Jonides study. In our experiment the cue spot disappeared, whereas in their study the letters did not disappear (only the irrelevant parts were removed). Miller (1989), using a paradigm similar to the Yantis and Jonides study but including disappearance of letters, in fact reached a somewhat different conclusion that attention is also drawn to offset transients.

The offset of a visual stimulus could produce totally different percepts depending on the global stimulus arrangements. It could indicate disappearance (complete offset), change in shape (partial offset), or change in position (shift in space). The above observations, taken together, may suggest that there is a critical difference between the disappearance and the change in shape in terms of the ability to induce attention. Our cxpcriment (Expt 7) indicated further that the change in position (step) is fundamentally different from the disappearance. 
Unlike in the offset case, the offset of the first stimulus in the step failed to produce attention (except for the very beginning); instead, attention appeared to shift from the location of the first stimulus toward the location of the second stimulus. A similar interaction might have occurred in the letter detection tasks such that any possible foci of attention produced by the partial offsets may be nullified by a powerful onset transient. A particularly interesting global effect in our experiment was apparent motion perceived from the offset site to the onset site. This suggests an intimate relationship between apparent motion and shift of attention. Apparent motion may simply reflect shift of attention; i.e. what we perceive in apparent motion might in fact be based upon the shift of attention. If so, whether or not the focus of attention moves smoothly along the path of apparent motion is an interesting question. The relationship between attention shift and apparent motion will be further discussed in the next section.

We have shown that attention can follow a moving object (Hikosaka et al., 1993); when multiple spots rotate around the fixation point and one of them is flashed, attention can easily follow the flashed spot, not captured at the flashed retinal location. The onset/offset interaction observed in the present study may underlie the smooth pursuit of attention. Note that in the present experiment the subjects were not required to follow the moving spot voluntarily with attention. Attention might thus be bound to a moving object, automatically to some extent, as suggested by (Kanwisher \& Driver, 1992).

\section{Relation of the line motion sensation to apparent motion}

The intimate relationship between attention shift and apparent motion naturally raises a question of whether the illusory motions is just a special artifact of apparent motion. There are several reasons why we do not think so. First, the motion sensation in our study has characteristics different from what defines apparent motion; that is, "when two neighboring visual stimulus objects are alternated in place at an appropriate rate, the observer sees a single object in movement between them" (Kolers, 1963). In our case, motion is perceived in a visual object, i.e. solid line, not between or outside visual objects. In this regard, our observation may be more relevant to a phenomenon labeled "gamma movement" which was reported by several researchers, including Ernst Mach, Max Wertheimer and Gaetano Kanizsa (Kanizsa, 1979): when a visual object is abruptly presented on a homogeneous background, it appears to expand. Second, the fact that both onset and offset of a visual stimulus produce the line motion sensation would be difficult to explain by apparent motion. According to the classical scheme, apparent motion should be produced away from the offset site and toward the onset site. In contrast, the line motion sensation was produced away from the onset site. The sequence is also reversed; unlike apparent motion, the line motion was perceived after the onset. The gamma movement would not account for these phenomena because it is a phenomenon that is observed when a visual object comes on, not goes off.

A stronger argument against apparent motion comes from our separate study in which attention was invoked purely voluntarily (Hikosaka et al., 1993). For example, a red square and a green square were presented at once, the observer attends to the square with the pre-instructed color, and then a probe line was presented between the squares. The same motion sensation, though somewhat weaker, was produced from the attended square. Apparent motion, whether short-range or long-range (Braddick, 1980), acts to solve the correspondence problem between sequential visual images (Anstis, 1980). In the experiment of voluntary attention, however, there was no physical changes in visual images for which the brain has to solve the correspondence problem.

Added to the above arguments are our recent observations. First, when the probe line is remote from the cue stimulus (up to several degree of visual angle), the motion sensation is still perceived in the line, not between the cue and the line (Miyauchi et al., 1992). Second, the motion sensation remains robust even when the cue, the line, and the background are different in color but isoluminant (unpublished observation). This is at variance with the observation that apparent motion can be abolished, or at least significantly weakened, in the isoluminant condition (Anstis, 1970; Ramachandran \& Gregory, 1978). Finally, even when the cue is in a non-visual modality such as auditory or somatosensory, the same visual line motion could be observed (Shimojo, Miyauchi \& Hikosaka, 1992).

\section{Time course of attention}

Our results suggested that the local facilitation caused by a cue stimulus is composed of a transient component and a sustained component. This is similar to the temporal characteristics obtained by Nakayama and Mackeben (1989). Discrimination of an odd stimulus among many non-odd stimuli is difficult if the oddness is defined by a conjunctive feature, requiring serial search with voluntary attention (Treisman \& Gelade, 1980). If, however, a visual cue is presented beforehand at the location of a possible odd stimulus, the discrimination becomes much easier depending on the cue lead time. The time course of such facilitation comprised of an initial transient phase followed by a sustained component.

These two components might correspond to and perhaps be caused by the transient and sustained neuronal responses in central visual areas (Breitmeyer \& Ganz, 1976). In fact, in our flash-line experiment in which the cue stimulus was no longer present when the probe line was presented (Fig. 6), the sustained component was uncommon or unclear. The reversal of facilitation in the cue-off experiment (Fig. 7) can be explained in the same manner: the offset of a 
cue stimulus would activate off-cells transiently while the remaining cue stimulus would keep activating sustained-type cells on the other side.

In contrast, Nakayama and Mackeben (1989) interpreted the sustained component as reflecting the voluntary or top-down control. In their study the cue stimulus indicated the location where attention was to be directed, whereas in our study the cue had no such predictive validity. We would accept their interpretation because when we asked the subject to hold attention to the flashed side (Hikosaka et al., 1993) (unlike in the present study), the local facilitation was maintained even though there was no longer a difference between the cued and uncued sides. Taken together these results, the sustained facilitation may be caused by at least two different processes-sensory and voluntary; attention may be held by the mere presence of a sensory stimulus or by voluntary effort.

Using a reaction time task, however, Posner and his colleagues (Posner, 1980; Posner \& Cohen, 1984; Posner, Cohen \& Rafal, 1982) reached a different conclusion. They demonstrated that the reaction time of button press in response to the appearance of a visual target was shortened if a visual cue was presented at the location of the stimulus whereas lengthened if the cue was on the other side. In this respect our results are in line with theirs in that both suggest the change in the speed of information processing. But there is a difference: a distinctive feature in the Posners results is that the information on the cued side is inhibited for a certain period after the facilitation, which they called "inhibition of return". This was never seen in our study.

The duration of precueing might be a factor to explain the difference. In Posner's experiments the cue stimulus was presented for a short period $(100-300 \mathrm{msec})$; by the time the inhibition of return became manifest, the cue stimulus was absent and thus could no longer anchor attention, unlike in our study or the Nakayama and Mackeben study.

The negative facilitation (inhibition of return), however, is still difficult to explain. In most of the Posner's experiments, the target appeared on the cued side or uncued side in an equal probability. Such uncertainty may require the subject to make a rapid serial search before making a motor response, yiclding the reversal of attention. No such time constraint was imposed in our study. Thus, the difference probably stems from the difference in behavioral measure: motor response in their case and perceptual speed in our case. The neural pathways leading to visual perception in our study and to motor response in the Posner's study are certainly different, although they should share the common visual pathway up to an unknown branching point. The difference, especially the inhibition, should occur after the motor-oriented information diverges from the common visual pathway.

This comparison may lead to the idea that the attention mechanism is distributed along different stages of information processing leading to motor acts. The distributed nature of attentional mechanisms was indicated by regional cerebral blood flow studies (Roland, 1982). Corbetta, Miezin, Dobmeyer, Shulman and Petersen (1991) using positron emission tomography (PET), demonstrated that attention-induced activation was observed at a whole variety of cortical as well as subcortical areas, but the activation pattern varies depending on the nature of task demands. Neurophysiologically, the effect of attention is demonstrated as the enhancement or suppression of sensory responses, but the nature of the modulatory processes is different among different brain areas (Goldberg \& Wurtz, 1972; Roland, 1982; Hikosaka \& Wurtz, 1983; Fischer \& Boch, 1985; Moran \& Desimone, 1985; Richmond \& Sato, 1987; Haenny \& Schiller, 1988; Haenny, Maunsell \& Schiller, 1988; Sato, 1988; Spitzer, Desimone \& Moran, 1988; Hikosaka et al., 1989; Fuster, 1990).

An intriguing possibility, in close relation to the allegedly distributed nature of attention mechanism, is that a cue in non-visual sensory modalities might also yield the same line motion effect in vision. We have already confirmed this with an auditory cue as well as a somatosensory cue (Shimojo et al., 1992).

\section{Attention and movement are both reflexive and voluntary}

There are common features between attention shift and body movement. Body movement is the way in which we manipulate the external environment. It is an active process. This does not necessarily mean, however, that body movement is always voluntary, under conscious control. It can be evoked by sensory inputs, as known to be reflex. Knee-jerk reflex or vestibulo-ocular reflex are typical examples. The distinction between reflex and voluntary movement is unclear, but there certainly exists a spectrum of movement, from the ones most reflex-like to the ones most voluntary. The relationship between reflex and voluntary movements is intimate: they are not exclusive but share common neural mechanisms. For example, there are two types of fast eye movement: quick phase of nystagmus which is reflexive and saccade which is more voluntary, both acting to reset visual images. Along with phylogenetic development, the visual areas, such as the superior colliculus, gained neural connections to the brainstem neural mechanisms for the quick reflexive phase, thus allowing a fast eye movement in response to a visual stimulus. This is what we call saccade. In other words, the neural mechanisms of voluntary movements are not separate from the mechanisms of reflexes; rather, the voluntary motor systems utilize the basic mechanisms of reflexes.

We speculate that the same principle holds for the neural mechanism of attention, as suggested previously (Posner, 1980; Jonides, 1981; Müller \& Rabbit, 1989). We have shown in a separate study (Hikosaka et al., 1993) that voluntary attention can be detected by the same line motion method, as mentioned above. The illusory motion has the same quality as the one described in the present study. Furthermore, the motion induced by voluntary attention and the motion induced by stimulus-induced attention interact, the latter being always dominant, albeit transiently. These data indeed 
suggest that voluntary type of attention may be phylogenetically newer, and activates the same mechanisms which serve for stimulus-induced, reflexive attention (Johnson, Posner \& Rothbart, 1991).

\section{REFERENCES}

Anstis, S. M. (1970). Phi movement as a substraction process. Vision Research, 10, 1411-1430.

Anstis, S. M. (1980). The perception of apparent movement. Philosophical Transactions of the Royal Society of London B, 290, 153-168.

Baker, C. L. \& Braddick, O. J. (1985). Temporal properties of the short range process in apparent motion. Perception, 14, 181-192.

Bashinski, H. S. \& Bacharach, V. R. (1980). Enhancement of perceptual sensitivity as the result of selectively attending to spatial locations. Perception and Psychophysics, 28, 241-248.

Biederman-Thorson, M., Thorson, J. \& Lange, G. D. (1971). Apparent movement due to closely spaced sequentially flashed dots in the human peripheral field of vision. Vision Research, 11, 889-903.

Braddick, O. (1980). Low level and high level processes in apparent motion. Philosophical Transactions of the Royal Society of London $B, 290,137-151$

Breitmeyer, B. G. \& Ganz, L. (1976). Implications of sustained and transient channels for theories of visual pattern masking, saccadic suppression, and information processing. Psychological Review, 83, 1-36.

Bruce, C. J., Desimone, R. \& Gross, C. G. (1981). Visual properties of neurons in a polysensory area in superior temporal sulcus of the macaque. Journal of Neurophysiology, 46, 369-384.

Corbetta, M., Miezin, F. M., Dobmeyer, S., Shulman, G. L. \& Petersen, S. E. (1991). Selective and divided attention during visual discriminations of shape, color, and speed: Functional anatomy by positron emission tomography. Journal of Neuroscience, II, 2383-2402.

Cynader, M. \& Berman, N. (1972). Receptive-field organization of monkey superior colliculus. Journal of Neurophysiology, 35, 187-201.

Desmedt, J. E. \& Robertson, D. (1977). Differential enhancement of early and late components of the cerebral somatosensory evoked potentials during forced-paced cognitive tasks in man. Journal of Physiology, London, 271, 761-782.

Downing, C. (1988). Expectancy and visual-spatial attention: Effects on perceptual quality. Journal of Experimental Psychology: Human Perception and Performance, 14, 188-202.

Eason, R. G. (1981). Visual evoked potential correlates of early neural filtering during selective attention. Bulletin of the Psychonomic Society, 18, 203-206.

Eason, R. G., Harter, M. R. \& White, C. (1969). Effects of attention and arousal on visually evoked cortical potentials and reaction time in man. Physiology and Behaviour, 4, 283-289.

Egly, R. \& Homa, D. (1984). Sensitization of the visual field. Journal of Experimental Psychology: Human Perception and Performance, 10, 778-793.

Eriksen, C. W. \& Hoffman, J. E. (1972). Some characteristics of selective attention in visual perception determined by vocal reaction time. Perception and Pshychophysics, 11, 169-171.

Finncy, D. J. (1971). Probit analysis. Cambridgc: Cambridge University Press.

Fischer, B. \& Boch, R. (1985). Peripheral attention versus central fixation: Modulation of the visual activity of prelunate cortical cells of the rhesus monkey. Brain Research, 345, 111-123.

Fuster, J. M. (1990). Inferotemporal units in selective visual attention and short-term memory. Journal of Neurophysiology, 64, 681-697.

Gattas, R. \& Desimone, R. (1991). Attention-related responses in the superior colliculus of the macaque. Society for Neuroscience Abstracts, 17, 545

Girard, P., Salin, P. A. \& Bullier, J. (1992). Response selectivity of neurons in area MT of the macaque monkey during reversible inactivation of area V1. Journal of Neurophysiology, $67,1437-1446$
Goldberg, M. E. \& Wurtz, R. H. (1972). Activity of superior colliculus in behaving monkey. II. Effect of attention on neuronal responses. Journal of Neurophysiology, 35, 560-574.

Graham, C. H. (1965). Vision and visual perception. New York: Wiley. Green, D. M. \& Henning, G. B. (1969). Audition. Annual Review of Psychology, 20, 105-128.

Haenny, P. E. \& Schiller, P. H. (1988) State dependent activity in monkey visual cortex. I. Single cell activity in V1 and V4 on visual tasks. Experimental Brain Research, 69, 225-244.

Haenny, P. E., Maunsell, J. H. R. \& Schiller, P. H. (1988). State dependent activity in monkey visual cortex. II. Retinal and extraretinal factors in V4. Experimental Brain Research, 69, 225-244.

Hernandez-Peon, R. (1967). Physiological mechanisms in attention. In Russell, R. W. (Eds), Frontiers in physiological psychology (pp. 121-147). New York: Academic Press.

Hikosaka, O. \& Wurtz, R. H. (1983). Visual and oculomotor functions of monkey substantia nigra pars reticulata. I. Relation of visual and auditory responses to saccades. Journal of Neurophysiology, 49, 1230-1253.

Hikosaka, O., Miyauchi, S. \& Shimojo, S. (1993). Voluntary and stimulus-induced attention detected as motion sensation. Perception. In press.

Hikosaka, O., Sakamoto, M. \& Usui, S. (1989). Functional properties of monkey caudate neurons. II. Visual and auditory responses. Journal of Neurophysiology, 61, 799.813.

Hillyard, S. A. (1985). Electrophysiology of human selective attention Trends in Neurosciences, 8, 400-405.

Hillyard, S. A. \& Picton, T. W. (1987). Electrophysiology of cognition. In Plum, F. (Eds), Higher functions of the brain (pp. 519-584). Bethesda, Md: American Physiological Society.

Hubel, D. H. \& Wiesel, T. N. (1961). Integrative action in the cats lateral geniculate body. Journal of Physiology, London, 155, 385-398.

Hubel, D. H. \& Wiesel, T. N. (1962). Receptive fields, binocular interaction and functional architecture in the cats visual cortex. Journal of Physiology, London, 160, 106-154

Johnson, M. H., Posner, M. I. \& Rothbart, M. K. (1991). Components of visual orienting in infancy: Contingency learning. anticipatory looking, and disengaging. Journal of Cognitive Neuroscience, 3, 335-344.

Johnston, W. A. \& Dark, V. J. (1982). In defense of intraperceptual theories of attention. Journal of Experimental Psychology: Human Perception and Performance, 8, 407-421.

Jonides, J. (1981). Voluntary versus automatic control over the minds eye. In Long, J. \& Baddeley, A. (Eds), Attention and performance IX (pp. 187-203). Erlbaum, N.J.: Hillsdale.

Kahneman, D. \& Treisman, A. (1984). Changing views of attention and automaticity. In Parasuraman, R. \& Davies, D. R. (Eds), Varieties of attention (pp. 29-62). New York: Academic Press.

Kanizsa, G. (1979). Organization in vision. New York.

Kanwisher, N. \& Driver, J. (1992). Objects, attributes, and visual attention: Which, what, and where. Current Directions in Psychological Science, 1, 26-31.

Kolers, P. A. (1963). Some differences between real and apparent visual movement. Vision Research, 3, 191-206.

Korte, A. (1915). Kinematoscopische Untersuchungen. Zeitschrift für Psychologie, 72, 193-296.

Kröse, J. A. \& Julesz, B. (1989). The control and speed of shifts of attention. Vision Research, 29, 1607-1619.

LaBerge, D. \& Brown, V. (1989). Theory of attentional operations in shape identification. Psychological Review, 96, 101-124.

LaBerge, D. \& Buchsbaum, M. S. (1990). Positron emission tomographic measurements of pulvinar activity during an attention task Journal of Neuroscience, 10, 613-619.

Ljungberg, T. \& Ungersteadt, U. (1976). Sensory inattention produced by 6-hydroxydopamine-induced degeneration of ascending dopamine neurons in the brain. Experimental Neurology, 53, 585-600.

Long, G. M. (1979). The dichoptic viewing paradigm: Do the eyes have it? Psychological Bulletin, 86, 391-403.

Mangun, G. R. \& Hillyard, S. A. (1988). Spatial gradients of visual attention: Behavioral and electrophysiological evidence. Electroencephalography and Clinical Neurophysiology, 70, 417428. 
Maylor, E. A. (1985). Facilitatory and inhibitory components of orienting in visual space. In Posner, M. I. \& Marin, O. S. A. (Eds), Attention and performance XI (pp. 189-204). Hillsdale, N.J.: Erlbaum.

Mikami, A., Newsome, W. T. \& Wurtz, R. H. (1986). Motion selectivity in Macaque visual cortex. II. Spatiotemporal range of directional interactions in MT and V1. Journal of Neurophysiology, $55,1328-1339$.

Miller, J. (1989). The control of attention by abrupt visual onsets and offsets. Perception and Psychophysics, 45, 567-571.

Miyauchi, S., Hikosaka, O.\& Shimojo, S. (1992). Visual attention field can be assessed by illusory line motion sensation. Investigative Ophthalmology and Visual Science, 33, 1262.

Moran, J. \& Desimone, R. (1985). Selective attention gates visual processing in the extrastriate corlex. Science, 229, 782-784.

Müller, H. J. \& Rabbit, P. M. A. (1989). Reflexive and voluntary orienting of visual attention: Time course of activation and resistance to interruption. Journal of Experimental Psychology: Human Perception and Performance, 15, 315-330.

Nakayama, K. (1985). Biological image motion processing: A review. Vision Research, 25, 625-660.

Nakayama, K. \& Mackeben, M. (1989). Sustained and transient components of focal visual attention. Vision Research, 29, 1631-1647.

Nakayama, K. \& Silverman, G. H. (1984). Temporal and spatial characteristics of the upper displacement limit for motion in random dots. Vision Research, 24, 293-299.

Nakayama, K. \& Tyler, C. W. (1981). Psychophysical isolation of movement sensitivity by removal of familiar position cues. Vision Research, 18, 427-433.

Newsome, W. T., Mikami, A. \& Wurtz, R. H. (1986). Motion selectivity in Macaque visual cortex. III. Psychophysics and physiology of apparent motion. Journal of Neurophysiology, 55, $1340-1351$.

Newsome, W. T., Britten, K. H., Movshon, J. A. \& Shadlen, M. (1989). Single neurons and the perception of visual motion. In Lam, D. M. \& Gilbert, C. D. (Eds), Neural mechanisms of visual perception (pp. 171-198). The Woodlands, Tex.: The Portfolio Publishing Company.

Posner, M. I. (1980). Orienting of attention. The VIIth Sir Frederic Bartlett Lecture. Quarterly Journal of Experimental Psychology, 32, 3-25.

Posner, M. I. \& Cohen, Y. (1984). Components of visual orienting. In Bouma, H. \& Bouwhuis, D. (Eds), Attention and performance $X$ (pp. 531-556). London: Erlbaum.

Posner, M. I., Cohen, Y. \& Rafal, R. D. (1982). Neural systems control of spatial orienting. Philosophical Transactions of the Royal Society of London B, 298, 187-198.

Posner, M. I., Rafal, R. D., Choate, L. S. \& Vaughan, J. (1985). Inhibition of return: Neural basis and function. Cognitive Neuropsychology, 2, 211-228.

Posner, M. I., Walker, J. A., Friedrich, F. J. \& Rafal, R. D. (1984). Effects of parietal injury on covert orienting of attention. Journal of Neuroscience, 4, 1863-1874.

Ramachandran, V. S. \& Gregory, R. L. (1978). Does colour provide an input to human motion perception? Nature, 275, 55-56.

Remington, R. W., Johnston, J. C. \& Yantis, S. (1992). Involuntary attentional capture by abrupt onsets. Perception and Psychophysics, $51,279-290$.

Richmond, B. I. \& Sato, T. (1987). Fnhancement of inferior temporal neurons during visual discrimination. Journal of Neurophysiology, $53,1292-1306$.

Robinson, D. L. \& McClurkin, J. W. (1989). The visual superior colliculus and pulvinar. In Wurtz, R. H. \& Goldberg, M. E. (Eds), The neurobiology of saccadic eye movements (pp. 337-360). Amsterdam: Elsevier.

Robinson, D. L., Goldberg, M. E. \& Stanton, G. B. (1978). Parietal association cortex in the primate: Sensory mechanisms and behav. ioral modulations. Journal of Neurophysiology, 41, 910-932.

Rodman, H. R., Gross, C. G. \& Albright, T. D. (1990). Afferent basis of visual response properties in area MT of the macaque. II. Effects of superior colliculus removal. Journal of Neuroscience, 10 , I154-1164.
Rogers, B. J. \& Anstis, S. M. (1972). Intensity versus adaptation and the Pulfrich stereophenomenon. Vision Research, 12, 909-928.

Roland, P. E. (1982). Cortical regulation of selective attention in man. A regional cerebral blood flow study. Journal of Neurophysiology, $48,1059-1078$.

Roufs, J. A. (1963). Perception lag as a function of stimulus luminance. Vision Research, 3, 8191.

Sagi, D. \& Julesz, B. (1986). Enhanced detection in the aperture of focal attention during simple discrimination tasks. Nature, 32l, 693-695.

Saito, H., Yukie, M., Tanaka, K., Hikosaka, K., Fukada, Y. \& Iwai, E. (1986). Integration of direction signals of image motion in the superior temporal sulucus of the macaque monkey. Journal of Neuroscience, 6, 145-157.

Sakata, H., Shibutani, H., Ito, Y. \& Tsurugai, K. (1986). Parietal cortical neurons responding to rotatory movement of visual stimulus in space. Experimental Brain Research, 61, 658-663.

Sato, T. (1988). Effects of attention and stimulus interaction on visual responses of inferior temporal neurons in macaque. Journal of Neurophysiology, 60, 344-364.

Shimojo, S., Miyauchi, S. \& Hikosaka, O. (1992). Visual motion sensation yielded by non-visually driven attention. Investigative Ophthalmology and Visual Science, 32, 1354.

Sparks, D. L. \& Hartwich-Young, R. (1989). The deep layers of the superior colliculus. In Wurtz, R. H. \& Goldberg, M. E. (Eds), The neurobiology of saccadic eye movements (pp. 213-255). Amsterdam: Elsevier.

Spitzer, H., Desimone, R. \& Moran, J. (1988). Increased attention enhances both behavioral and neuronal performance. Science, 240 , 338- 340

Stelmach, L. B. \& Herdman, C. M. (1991). Directed attention and perception of temporal order. Journal of Experimental Psychology: Human Perception and Performance, 17, 539-550.

Sternberg, S. \& Knoll, R. L. (1973). The perception of temporal order: Fundamental issues and a general model. In Kornblum, $\mathrm{S}$. (Ed.), Attention and performance IV (pp. 629-685). New York: Academic Press.

Tanaka, K. \& Saito, H. (1989). Analysis of motion of the visual field by direction, expansion/contraction, and rotation cells clustered in the dorsal part of the medial superior temporal area of the macaque Inonkey. Journal of Neurophysiology, 62, 626-641.

Treisman, A. M. \& Gelade, G. (1980). A feature-integration theory of attention. Cognitive Psychology, 12, 97-136.

Ungerleider, L. G. \& Desimone, R. (1986). Cortical connections of visual area MT in the macaque. Journal of Comparative Neurology, $248,190-222$.

Van Essen, D. C., Maunsell, J. H. R. \& Bixby, J. L. (1981). The middle temporal visual area in the macaque: myeloarchitecture, connections, functional properties and topographic organization. Journal of Comparative Neurology, 199, 293-326.

Wertheimer, M. (1912). Experimetelle Studien über das Sehen von Bewegung. Zeitschrift für Psychologie, 61, 161-278.

Wurtz, R. H. \& Mohler, C. W. (1976). Enhancement of visual responses in monkey striate cortex and frontal eye fields. Journal of Neurophysiology, 39, 766-772.

Wurtz, R. H., Goldberg, M. E. \& Robinson, D. L. (1980). Behavioral modulation of visual responses in the monkey: Stimulus selection for attention and movement. In Sprague, J. M. \& Epstein, A. N. (Eds), Progress in psychobiology and physiological psychology (Vol. 9), (pp. 43-83). New York: Academic Press.

Yantis, S. \& Jonides, J. (1984). Abrupt visual onsets and selective attention: Evidence from visual search. Journal of Experimental Psychology: Human Perception and Performance, 10, 601-621.

Zeki, S. M. (1974). Functional organization of a visual area in the posterior bank of the superior temporal sulcus of the rhesus monkey. Journal of Physiology, London, 236, 549-573.

Acknowledgement-S. Shimojo is supported partly by Grant-in-Aid for Creative Basic Research from The Ministry of Education, Science and Culture of Japan. 